

\section{DISCLAIMER}

This report was prepared as an account of work sponsored by an agency of the United States Government. Neither the United States Government nor any agency Thereof, nor any of their employees, makes any warranty, express or implied, or assumes any legal liability or responsibility for the accuracy, completeness, or usefulness of any information, apparatus, product, or process disclosed, or represents that its use would not infringe privately owned rights. Reference herein to any specific commercial product, process, or service by trade name, trademark, manufacturer, or otherwise does not necessarily constitute or imply its endorsement, recommendation, or favoring by the United States Government or any agency thereof. The views and opinions of authors expressed herein do not necessarily state or reflect those of the United States Government or any agency thereof. 


\section{DISCLAIMER}

Portions of this document may be illegible in electronic image products. Images are produced from the best available original document. 


\section{$\begin{array}{llllllllllllllll}\text { C } & \text { F } & \text { B } & \mathrm{R} & \text { A } & \text { U } & \text { N } & \& & \text { C } & \text { O }\end{array}$ \\ Engineers \\ A L H A M B R C A L I F O R N I 918002}

February 4, 1969

Mr H B Fry
Contracting officer, contract AT (04-3)-781
AEC San Francisco
2111 Bancroft Way
Berkeley, California 94704
Dear Mr Fry
A STUDY OF FAILURE THEORIES
TECHNICAL REPORT 210
LMFBR PIPING DESIGN GUIDE
AEC SAN FRANCISCO
PROJECT 4122-W

Transmitted herewith are two copies of the draft report covering studies of failure theories as related to LMFBR piping systems.

The purpose of the study was to survey existing theories for predicting the imminence of failure and selecting those which provide an adequate basis for developing design procedures. Evaluation of these theories to cover the many modes of failure possible for LMFBR piping systems has proved to be more involved and time consuming than originally estimated. For that reason we have elected to divide the work into two parts for reporting purposes. The first part will cover the survey and applicability of failure theories. The second part will treat the problem of evaluating the applicable theories for the solution of design problems associated with the possible modes of failure of LMFBR piping systems.

This report deals with the survey and applicability of existing theories. Work on the second part is in progress and will be reported upon as soon as possible. 
The present report contains a substantial amount of detailed mathematical explanation of the methods used for analysis. Inclusion of this material in the body of the report is of questionable value to reviewers who are not interested in the detailed procedures. Subsequent issues of the report may delete this material or relocate it in an appendix. Comments on these alternatives are solicited.

A five-week period is allowed for review and return of comments to Braun. Comments should be mailed by March 7 to

C F Braun \& Co Dr R F Detman, Project Manager Alhambra, California 91802

RFD IV

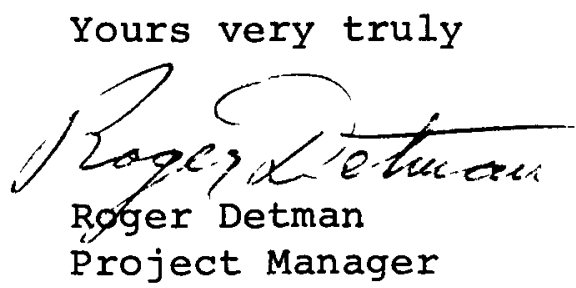

CC H B Fry, Contracting officer -original and one

Director, RDT, HQ Asst. Director, Plant Engineering, RDT, HQ RDT Senior Site Representative (AI) -2 Director, LMEC -8 
CFB 4122-210

UNC -5235

\title{
A STUDY OF FAILURE THEORIES AS RELATED TO LMFBR PIPING SYSTEMS
}

Technical Report 210

\begin{abstract}
This report was prepared as an account of work sponsored by the prepared as an account of work the United States nor the United States Atomic Energy Commission, nor any of their employees, Enic Energy their contractors, subcontractors, or their employees makes any legal liability or res any pleteness or usefulness of any for the accuracy, completeness or usefulness of any information, apparatus,
product or process disclosed, or represents product or process disclosed, or represents that its use would not infringe privately owned rights.
\end{abstract}

Prepared for U. S. Atomic Energy Commission

Contract No. AT(04-3)-781

Braun Project 4122-W

United Nuclear Project 2351

UNITED NUC LEAR CORPORATION

Research and Engineering Center

Elmsford, New York

January 31, 1969 


\section{PRELIMINARY}


TABLE OF CONTENTS

1. INTRODUCTION $\ldots \ldots \ldots \ldots \ldots \ldots \ldots \ldots \ldots \ldots \ldots \ldots \ldots \ldots \ldots \ldots$

2. GENERAL DISCUSSION $\ldots \ldots \ldots \ldots \ldots \ldots \ldots \ldots \ldots \ldots \ldots \ldots \ldots \ldots$

3. FAILURE MECHANISMS IN LMFBR PIPING

SYSTEMS ....................... $3-1$

3. 1 Excessive Primary Load ................ 3-1

3.1.1 Excessive Primary Membrane

Stress ...................... 3-1

3.1.2 Ductile Rupture ................. 3-1

3.1.3 Creep Rupture ................... 3-1

3.1.4 Excessive Gross Distortion ........... 3-2

3.1.5 Elastic, Plastic, or Creep Instability .... 3-4

3.2 Brittle Fracture ................... 3-4

3.3 Crack Formation and Propagation ............ 3-5

3. 4 Environmental Material Deterioration ......... 3-5

4. REVIEW OF FAILURE THEORIES ............. 4-1

4. 1 Maximum Principal Stress Theory ............ 4-2

4. 2 Maximum Shear Stress Theory (Tresca) ........ 4-2

4. 3 Distortion Energy Theory (von Mises) ......... 4-3

5. APPLICATION OF FAILURE THEORIES AND

ANALYTICAL METHODS TO FAILURE MECHANISMS .. 5-1

5. 1 Excessive Primary Load ............... 5-1

5. 1. 1 Excessive Primary Membrane Stress .... 5-1

5. 1. 2 Ductile Rupture ................ 5-3

5.1.3 Creep Rupture ................ 5-9

5.1.4 Excessive Gross Distortion ......... 5-19

5.1.5 Elastic, Plastic, or Creep

Instability ................. 5-36

5. 2 Brittle Fracture ................. 5-37

5. 2. 1 Fracture Analysis Diagram Approach .... 5-37

5.2. 2 Summary and Recommendations ....... 5-45

5. 3 Crack Formation and Propagation ........... 5-46

5. 3. 1 ASA Piping Code ............... 5-47

5.3.2 ASME Code................... 5-48

5.3.3 Approximate Methods of High-Tempera-

ture Fatigue Evaluation ............. 5-52

5. 3.4 Local Strain Concentration ........... 5-63

5.3.5 Summary ................... 5-63

5.4 Local Strain Concentrations ............. 5-64 
6. RECOMMENDED R\&D REQUIREMENTS . . . . . . . . . 6-1

6.1 Ductile Rupture ....................6-1

6.2 Excessive Distortion .................. 6-1

6.3 Brittle Fracture .................. 6-2

6.4 Fatigue ........................ $6-3$

6. 5 Local Strain Concentrations ..............6-3

7. BIBLIOGRAPHY ..................... $7-1$

Appendix A - Historical Events Leading to the New

ASME Code Tube Formula ............... A-1 
TABLE

5. 1 Summary of Code Primary Stress Bases Current and Suggested ......................... 5-11

\section{FIGURES}

1. 1 Inter relationship Diagram - Task Area 3-8 - Coolant Transport and Storage Systems ................ 1-2

3. 1 Uniaxial Stress Regimes - Sustained Primary Stress vs Cyclic Secondary Stress (after Bree) ........... 3-3

5. 1 Actual Relationship of Critical Crack Length and Failure Stress ......................... 5-7

5.2 Illustration of Use of Life Fraction Rule .......... 5-15

5. 3 Illustrative Creep Curve for Uniaxial Tensile Loading - Dashed Line Shows Behavior on Unloading ... 5-20

5. 4 Schematic Flow Diagram - Computational Procedures for Multiaxial Thermoelastic - Plastic-Creep StressStrain Analysis ....................... 5-23

5. 5 Uniaxial Stress Regimes - Mean Stress vs Thermal Stress Range for Linear Temperature Gradient . . . . . . 5 53

5. 6 Transition Temperature Features of Steels ......... 5-38

5. 7 Generalized Fracture Analysis Diagram, as Referenced by the NDT Temperature .................. 5-40

5. 8 An Example Illustrating the Four Simple Steps for the Engineering Selection of Fracture-Safe Steels Based on the Fracture Analysis Diagram Concepts and a Catalog of NDT Data . . . . . . . . . . . . . . . .

5. 9 Design Fatigue Strength, $\mathrm{S}_{\mathrm{a}}$, for Carbon and Low-Alloy Steels through $5 \% \mathrm{Cr}$ up to $1100 \mathrm{~F} \ldots \ldots \ldots \ldots \ldots . \ldots . . . . .59$

5. 10 Design Fatigue Strength, $\mathrm{S}_{\mathrm{a}}$, for High-Alloy Steels and Nickel-Chrome-Iron Alloy at to $1200 \mathrm{~F} \ldots \ldots . . . \ldots$. . . 5-50

5. 11 Plastic-Strain Range vs Cycles to Failure for Annealed Fe-0.1\% C-2. $0 \%$ Mo, Based on Fracture Ductility at

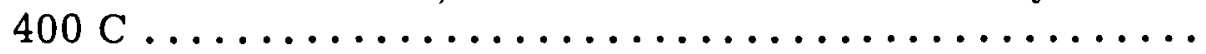

5. 12 Ductility Normalized Plastic-Strain Range vs Cycles to Failure for Annealed Fe-0.1\% C-2. 0\% Mo Steel ..... . 5 5-55

5. 13 Method of Universal Slopes for Estimating Axial Fatigue Life ... . . . . . . . . . . . . . . . . . . . . 5-57

5.14 Criterion to Establish Need for Creep-Rupture Correction ......................... 6-61 


\section{INTRODUCTION}

C. F. Braun \& Company, with United Nuclear Corporation as subcontractor, has been awarded a contract* by the U. S. Atomic Energy Commission for the development and verification of a Piping Design Guide for sodium-cooled fast breeder reactor power plants (LMFBR). The work is a Priority 1 Task under the LMFBR Program Plan $\dagger$ prepared for USAEC Division of Reactor Development and Technology (RDT) by the LMFBR Program Office, Argonne National Laboratory. It is identified in the Program Plan as Task 3-8.2, Development of Design Technology for Piping.

This Technical Report identifies major stress or strain governed failure mechanisms of LMFBR piping systems and summarizes present state-of-the-art methods to predict the imminence of failure by these mechanisms.

A review procedure has been established to insure coordination of interdependent studies currently being performed under this and other task areas of the LMFBR Program Plan. Under the review procedure, the Liquid Metal Engineering Center (LMEC) is the coordinating agency. Technical Reports prepared by Braun under this contract will be distributed by LMEC to appropriate Review Agencies designated by the USAEC. Comments from Review Agencies will be evaluated by Braun; United Nuclear to determine their validity. Valid comments will then be incorporated into subsequent revisions to the Technical Reports.

Fig. 1.1 shows the interrelationship of tasks under Task Area 3-8, Coolant Transport and Storage Systems.

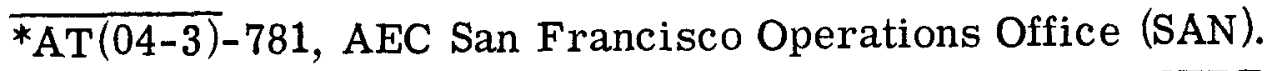
†Liquid Metal Fast Breeder Reactor Program Plan, LMFBR Program Office, Argonne National Laboratory, AEC R\&D Report, Reactor Technology, WASH-1101 (Aug. 1968). 


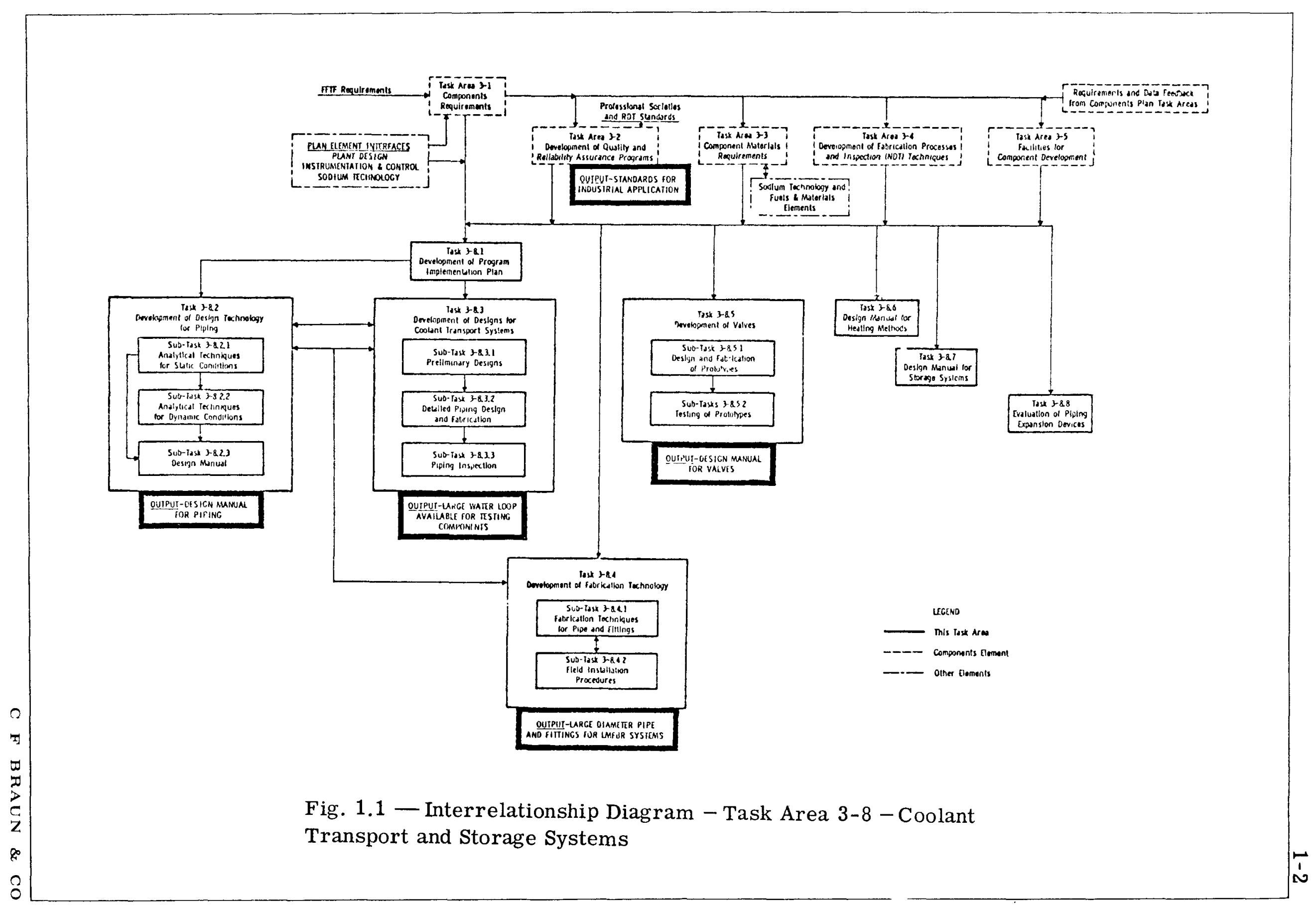


3. FAILURE MECHANISMS IN LMFBR PIPING SYSTEMS

\section{1 EXCESSIVE PRIMARY LOAD}

\subsubsection{Excessive Primary Membrane Stress}

Failure may be due to tensile stress caused by a primary load such as internal pressure, or an axial mechanical load which exceeds the ultimate tensile strength. A characteristic of this action is a reduction of the area resisting the load overtaking the strain hardening of the metal. That is, the area is reduced at a faster rate than the increase of material strength due to strain hardening. This is equivalent to the necking of a simple tensile specimen.

\subsubsection{Ductile Rupture}

This is a low-energy ductile fracture at nominal stresses below yield in the presence of large crack-like defects. This mechanism can occur in the bursting of a pressure vessel or pipe due to either local thinning or the propagation of a crack.

\subsubsection{Creep Rupture}

At elevated temperatures, where deformation due to creep may occur, either excessive deformation or creep rupture, which in the creep range is a failure mechanism corresponding to ductile rupture, may occur. 


\subsection{Excessive Distortion}

Excessive distortion can result from steady creep, or it can be a plastic deformation due to excessive loads which render the piping or associated equipment inoperative.

Excessive distortion may occur in LMFBR piping systems under various combinations of steady-state and cyclic loadings. To facilitate classification of the conditions of stress which may exist under such loadings, Bree ${ }^{52}$ 53,54 $^{34}$ has suggested the "stress regime" concept illustrated in Figure 3.1, and discussed more fully in 5.1.4 (E). By this concept, piping may be in one of four stress regimes, depending upon the intensity of the primary and cyclic secondary stresses, as follows.

\section{Elastic Regime (No Yielding)}

In this regime deformations resulting from the loads are elastic, and progressive distortion does not occur from cyclic application of the load.

2. Shakedown Regime - Plastic Flow and Growth Occur on Initial Cycles Only

The "shakedown theorem" of plasticity states that shakedown will occur if and only if a state of self-stress can be found such that superposition of the presented cycles of load and temperature on this state of self-stress nowhere leads to a violation of the yield condition.

\section{Plastic Cycling Regime (Nonratcheting)}

Plastic flow occurs on each cycle, but the progressive distortion increment decreases for each subsequent cycle, and finally ceases.

\section{Ratcheting Regime (Incremental Distortion)}

Ratcheting is characterized by a monotonic plastic distortion resulting from the successive application of cyclic loads superimposed upon a steady-state load. Plastic flow occurs as the cyclic load is applied, followed by only a partial strain reversal during unloading, resulting in a successive accumulation of plastic strain. 


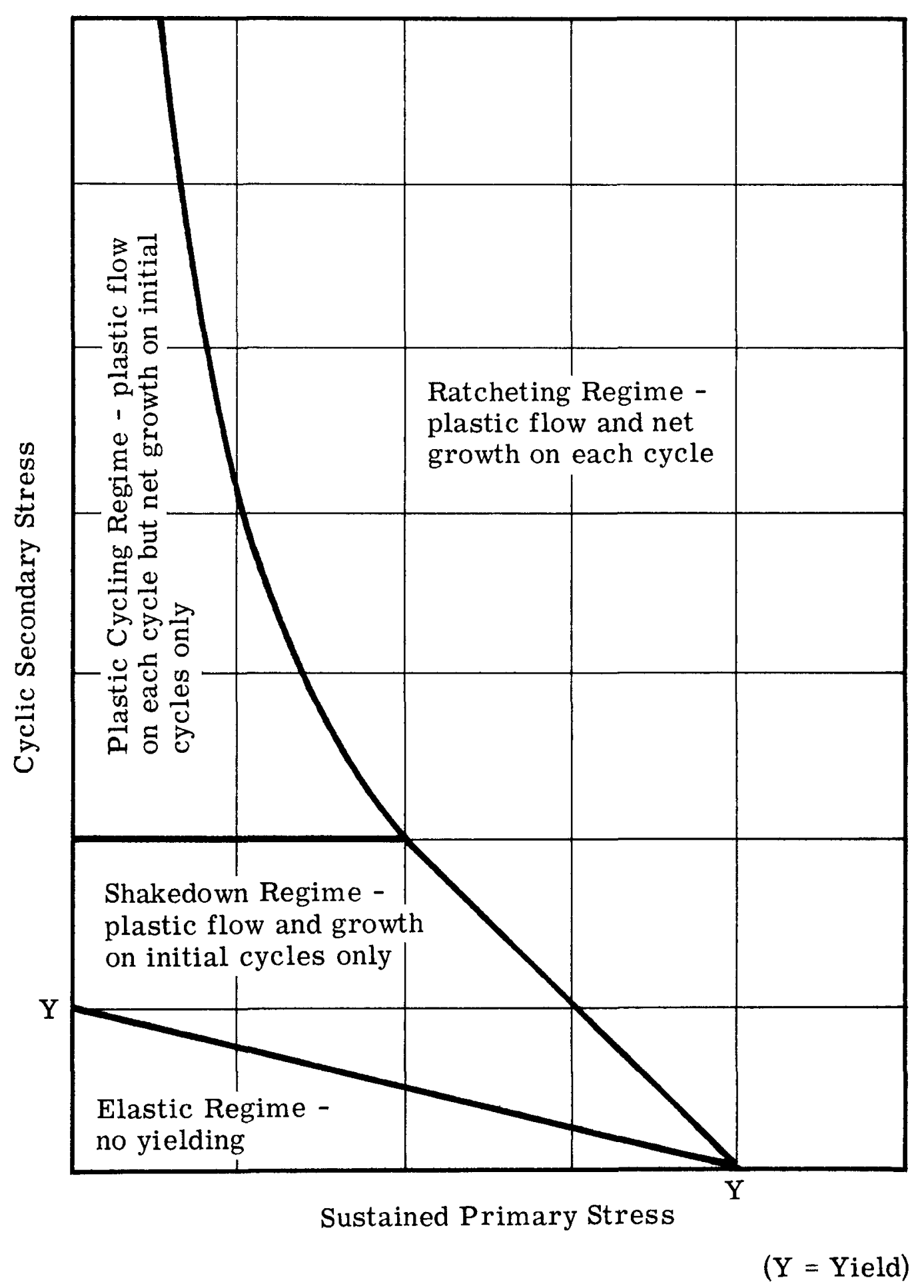

Fig. 3. 1 - Uniaxial Stress Regimes - Sustained Primary Stress vs Cyclic Secondary Stress (after Bree) 


\subsubsection{Elastic, Plastic, or Creep Instability}

Compressive stresses in piping components can result in failure due to buckling. This condition can be aggravated by eccentricities or initial deformations associated with manufacturing tolerances. Deflections may be elastic, plastic, or the result of creep. This condition of instability may apply, for example, to a long straight pipe acting as a column, to an elbow subjected to a bending load, or to a cylindrical section of pipe under external pressure.

\section{2 BRITTLE FRACTURE}

Brittle fractures are characterized by the propagation of cracks at velocities of several thousand feet per second. The fractures are normal to wall surfaces (square-break) and of crystalline texture, indicating that the individual grains of the steel fractured by cleavage of crystal planes. In general, there is little evidence of plastic flow except for thin fins or "shear lips" at the free surfaces of the crack. In contrast, ductile fractures show a 45-degree shear tear involving plastic deformation of the individual grains; in effect the shear lip covers the entire fracture surface. Except for certain types of ultrahigh-strength alloys, and nonferrous alloys, the 45-degree shear fractures develop only by the application of gross plastic overloads approaching the ultimate tensile strength of the steel. The propagation of such fractures proceeds only at the rates of continued reapplication of the plastic overloads, and therefore, with very high-energy absorption. Brittle fractures, on the other hand, are propagated in a manner which may be described as "spontaneous" in that the driving energy is less than the release of strain energy, and derived from it.

For the materials considered in this study for use in LMFBR piping systems, brittle fracture is a consideration only for $21 / 4 \mathrm{Cr}$ 1 Mo steel, and only for loading conditions that exist when the plant has been cooled to ambient conditions. 


\section{3 CRACK FORMATION AND PROPAGATION}

Under cyclic stress or strain, fatigue-induced fracture may result from the propagation of a crack transecting the material. The crack may start as a relatively minor defect such as a surface scratch or internal flaw; or it may be self-initiated, as a displacement along a slip plane within the grain boundaries. In either case the crack may migrate from the point of initiation, through adjacent grains and to the metal surface.

Of special concern in LMFBR piping is the initiation of cracks in local soft spots, such as might be induced by welding, where cyclic plastic strains can be localized. Here, because of differences in material properties resulting from such effects, a plastic hinge is possible, which may cause accelerated fatigue cracking.

Another contributory cause of fatigue cracking may be the existence of high stress concentrations in the vicinity of a structural or material discontinuity. In this category are discontinuities at a branch connection, reinforcement pad, or a support lug, and notches due to misalignment at a circumferential or longitudinal butt weld.

Fatigue cracking is a phenomenon of which the designer can have no prior knowledge. Furthermore, its initiation may escape detection by the inspection methods of the manufacturer and fabricator of the piping. Its prediction by quantitative methods is therefore impossible, although the liklihood of its occurrence may be reduced by the implementation of careful design, manufacturing and fabrication practices which minimize contributory defects of the kind described above.

\section{4 ENVIRONMENTAL MATERIAL DETERIORATION}

This classification includes any material degradation in which a structural element fails to carry a load which it carried at an earlier time. This may be due to mass transfer, corrosion, decarburization, carburization, or erosion. In some cases, material properties may be reduced, and in others, cracks may be initiated, either of which can lead to failures. 


\section{REVIEW OF FAILURE THEORIES}

A significant amount of the difficulty encountered in structural analysis stems from the fact that we can solve relatively few threedimensional stress problems. Therefore, approximations are made, reducing the problem to a two- or one-dimensional problem that can be solved. In the process of solving the simplified problem, the approximations that have been made may be forgotten. All structural members are three-dimensional, and when they fail, they fail as three-dimensional bodies, and not as idealized one- or two-dimensional bodies.

Failure by yielding in a simple tension or compression test specimen is well defined by the stress-strain diagram. For an element subjected to multiaxial stresses, the problem is not so simple, since the magnitude of a principal stress required to cause yielding is influenced by the magnitude of the other principal stresses. Various theories of failure, sometimes called theories of strength, have been proposed to handle this situation. In general, these theories consider that failure by yielding (plastic flow) occurs when the general level of stress, strain, or strain energy for the three-dimensional body is equivalent to the corresponding value of stress, strain, or strain energy at yield in simple tension or compression.

In addition to being of use in predicting the onset of yield under multiaxial stress conditions, these theories and associated formulations are used to predict the amount and direction of plastic flow, and to predict triaxial creep rates from uniaxial creep data. 
The three most common theories of failure are the maximum principal stress theory (Mohr), the maximum shear theory (Tresca), and the elastic strain energy theory (von Mises). For more detailed descriptions of these theories, as well as other theories, the reader is referred to one of the numerous texts covering the subject (References 32 through 35 ).

\section{1 MAXIMUM PRINCIPAL STRESS THEORY}

This theory states that yielding or failure will occur when the largest of the principal stresses exceeds the yield strength or the ultimate strength of the material. To compare with other theories where an "equivalent stress" may be compared to the yield strength or some other design criteria, the equivalent stress may be expressed as

$$
\mathrm{S}_{\mathrm{e}}=\left(\sigma_{\mathrm{i}}\right)_{\max }, \quad \mathrm{i}=1,2,3 \quad \sigma_{\mathrm{i}}=\text { principal stress }
$$

The maximum stress criterion may be used to describe the behavior of brittle materials, but for ductile materials it does not provide as good agreement with experiment as the maximum shear or distortion energy theories.

\section{2 MAXIMUM SHEAR STRESS THEORY (TRESCA)}

This theory assumes that yielding will occur when the maximum shear stress in the body equals the maximum shear stress in a tensile specimen when the material reaches yield.

Since

$$
\tau_{\max }=\frac{1}{2}\left|\sigma_{1}-\sigma_{2}\right| \text {, where } \tau=\text { shear stress, }
$$

and in a tensile specimen $\sigma_{1}=\mathrm{S}_{\mathrm{y}}, \sigma_{2}=0, \sigma_{3}=0$,

$$
\tau_{\max }=1 / 2 \mathrm{~S}_{\mathrm{y}}
$$

It is assumed that for more complicated stress loadings the limiting shear stress will continue to be

$$
\tau_{\max }=\frac{1}{2} S_{\mathrm{y}}
$$

and since it can be shown by considerations of equilibrium that 


$$
\tau \max =1 / 2\left|\sigma_{1}-\sigma_{2}\right|
$$

it follows that

$$
S_{y}=\left|\sigma_{1}-\sigma_{2}\right| \text {. }
$$

Since there are other planes of shear stress, and the maximum absolute value is of interest, a more general yield criterion is

$$
S_{y}=\left|\sigma_{i}-\sigma_{j}\right|_{\max } ; i=1,2,3 ; j=1,2,3
$$

If some stress value other than the yield strength, $\mathrm{S}_{\mathrm{y}}$, is to be used as a design criterion, the equivalent stress may be defined as

$$
S_{e}=\left|\sigma_{i}-\sigma_{j}\right|_{\max } ; \quad i=1,2,3 ; j=1,2,3
$$

The primary advantages of the maximum shear theory are good (but generally conservative) agreement with experimental data, ease of calculation due to the simplified nature of the equations, and it does offer some advantages in certain applications to fatigue analysis. Because the maximum difference of pairs is involved, mathematical irregularities sometimes arise, and there is no characteristic direction of the equivalent stress.

\subsection{DISTORTION ENERGY THEORY (VON MISES)}

This theory is based on experimental evidence that the distortion component of the elastic strain energy stored in a stressed element is a good criterion of failure. By equating the general expression for this energy component, (in terms of the stress components and the elastic constants $)$ to the distortion energy for a simple tensile specimen at the yield point, the following formula is obtained:

$$
\mathbf{S}_{\mathrm{y}}=\left\{1 / 2\left[\left(\sigma_{1}-\sigma_{2}\right)^{2}+\left(\sigma_{2}-\sigma_{3}\right)^{2}+\left(\sigma_{3}-\sigma_{1}\right)^{2}\right]\right\}^{1 / 2}
$$

And again to utilize the concept of an equivalent stress, this becomes

$$
\mathrm{S}_{\mathrm{e}}=\left\{1 / 2\left[\left(\sigma_{1}-\sigma_{2}\right)^{2}+\left(\sigma_{2}-\sigma_{3}\right)^{2}+\left(\sigma_{3}-\sigma_{1}\right)^{2}\right]\right\}^{1 / 2}
$$

and the equivalent plastic strain is: 


$$
\epsilon_{e p}=\frac{\sqrt{2}}{3}\left[\left(\epsilon_{1 p}-\epsilon_{2 p}\right)^{2}+\left(\epsilon_{2 p}-\epsilon_{3 p}\right)^{2}+\left(\epsilon_{3 p}-\epsilon_{1 p}\right)^{2}\right]^{1 / 2}
$$

The principal advantage of the elastic strain energy theory is that it gives the best agreement with experimental values for a wide variety of conditions of any of the many theories. A lesser advantage is the mathematical uniformity resulting from a single formula, rather than three which may be encountered with the maximum shear theory. The main disadvantage is the increased calculation required by the more complicated formula. 


\section{APPLICATION OF FAILURE THEORIES AND ANALYTICAL METHODS TO FAILURE MECHANISMS}

In the following subsections design approaches to predict the imminence of failure, or to establish a rational basis to design against failure by the mechanisms delineated in Section 3 are reviewed.

\section{1 EXCESSIVE PRIMARY LOAD}

\subsubsection{Excessive Primary Membrane Stress}

To design against the simplest form of gross primary overload, excessive primary membrane stress, such as that caused by internal pressure, direct mechanical (or weight) loads, etc., current pressure vessel (ASME, Section III) and piping (USASI B31. 7) codes require use of the maximum shear theory (TRESCA). This permits designation of a "stress intensity" value, equal to twice the maximum shear stress, which can be compared directly with an allowable stress based on a fraction of the yield strength or ultimate tensile strength of the material, i. e., $1 / 3$ UTS or $2 / 3$ YS, whichever is lower.

Most experiments show that the distortion energy theory is somewhat more accurate than the shear theory in predicting the onset of yielding. For LMFBR piping systems either approach is suitable for establishing criteria to provide a suitable margin of safety against yielding under general membrane stresses. However, as will be discussed in Section 5. 1.3 criterion to provide a margin of safety against failure by creep rupture might also be based on limiting primary stresses. A problem arises in that for creep rupture under a multiaxial stress state some materials appear to satisfy the maximum principal stress criterion, while others appear to satisfy the distortion energy criterion. 
Since it is desirable to have a single failure theory and associated formulations provide the margins against failure by yielding and creep rupture, final selection of the approach is dependent upon resolution of this problem. Further evaluations aimed at resolving this problem are currently being performed, and recommendations in this area will be made in a separate Technical Report (211).

Another consideration is the bursting strength of the piping when subjected to a gross pressure overload. If the required wall thickness of the piping is intended to give a known factor of safety against gross overpressure, then use of a formula which provides reasonably accurate predictions of the piping burst strength is required. Langer ${ }^{3} 6$ has reviewed possible approaches to the problem, compared the predictions of various formulae with experimental data, and recommended a set of formulae which requires only a knowledge of the ultimate strength and uniform elongation. These formulae can be expected to predict bursting strength of piping within \pm 10 percent, provided the material is sufficiently ductile to reach the point of plastic instability without cleavage or shear failure. The formulae recommended by Langer for bursting pressure are:

$$
\mathrm{p}_{\mathrm{b}}=\sigma_{\mathrm{u}}, \mathrm{F}_{\text {cyl }} \frac{2 \mathrm{t}}{\mathrm{d}_{\mathrm{i}}}\left(1-\frac{\mathrm{t}}{\mathrm{d}_{\mathrm{i}}}\right)
$$

for $\left(d_{i}+t\right) / d_{i} \leqslant 1.4$, and

$$
\mathrm{p}_{\mathrm{b}}=\sigma_{\mathrm{u}^{\prime}} \mathrm{F}_{\mathrm{cyl}} \ln \left[\left(\mathrm{d}_{\mathrm{i}}+\mathrm{t}\right) / \mathrm{d}_{\mathrm{i}}\right]
$$

for $\left(d_{i}+t\right) / d_{i}>1.4$,

where $\mathrm{p}_{\mathrm{b}}=$ bursting pressure, psi

$\mathrm{t}=$ thickness of cylinder, in.

$\mathrm{d}_{\mathrm{i}}=$ cylinder inside diameter, in.

$\sigma_{\mathbf{u}^{\prime}}=$ nominal (engineering) stress at ultimate load, psi

$\mathbf{F}_{\text {cyl }}=$ a factor used in cylinder bursting strength formula which is given as a function of nominal (engineering) strain at ultimate load. 


\subsubsection{Ductile Rupture}

This failure mechanism is associated with gross structural or intergranular defects (cracks) at nomin?: stresses below yield. For this failure mode to exist in LMFBR iping large cracks, or local thinning of the pipe wall, would have occurred subsequent to installation and prior to failure, and passed undetected. It could ensue abruptly following a major detrimental excursion from controlled conditions which induced local loading in excess of those for which the system or component was designed. Because of the unpredictable nature of the conditions giving rise to failure from ductile rupture, it is not possible to evaluate its significance to design criteria in quantitative terms at the present time.

A program is now in progress at Battelle Memorial Institute (References 6 through 10) to determine what size defects in typical reactor coolant piping are required to produce unstable propagating fractures under boiling water and pressurized water conditions. To accomplish this, full-scale tests are being conducted on reactor piping containing artificial defects under simulated service conditions. The influence of important factors such as pipe radius, wall thickness, and material also will be investigated. Experiments will be conducted on cracks entirely through the wall and surface cracks partially through the wall. Data with respect to the extent of unstable propagation will be obtained. Materials being investigated are A106-B carbon steel and Type 316 stainless steel.

Recently, the capability has been developed at BMI to predict critical flaw sizes in relatively thin-walled piping and pressure vessels. The difficulties in the past have been that the concepts employed for linear elastic fracture mechanics have been unsuitable for materials that exhibit considerable ductility under service conditions, and that these concepts were developed for flat plates which have different stress fields under load than cylinders. The above theoretical formulations for predicting critical crack lengths are being employed to determine their validity with thick-walled reactor piping.

Over the past several years, considerable work has been conducted at Battelle in the area of critical crack length determination in cylindrical pressure vessels and piping. One of the results of this work has been a theoretical formulation of the relationship of critical crack length to failure stress in terms of a stress intensity factor, $\mathrm{K}$. 
Eq. 5.3 presents the relationship that has been developed for $\mathrm{K}$ as a function of longitudinal through-the-wall crack length and nominal stress level for cylinders under external pressure.

$$
\mathrm{K}^{2}=\frac{\pi \mathrm{c} \sigma_{\mathrm{h}}^{2}}{\cos \theta}\left(1+\frac{5 \pi}{32} \lambda^{2}\right)\left(\frac{4-\kappa}{2}\right),
$$

where $\mathrm{K}=$ stress intensity factor, $\mathrm{ksi} \sqrt{\mathrm{in}}$.

$\mathrm{c}=$ half of the crack length (through-the-wall cracks), in.

$\lambda^{2}=\left(\mathrm{c}^{2} / \mathrm{Rt}\right) \sqrt{12\left(1-\nu^{2}\right)}$

$\nu=$ Poisson's ratio 


$$
\begin{aligned}
\mathrm{R} & =\text { radius of vessel, in. } \\
\mathrm{t} & =\text { wall thickness, in. } \\
\theta & =(\pi / 2)\left(\sigma_{\mathrm{h}} / \sigma_{\mathrm{c}}\right) \\
\sigma_{\mathrm{h}} & =\text { nominal circumferential stress, ksi } \\
\sigma_{\mathrm{c}} & =\text { failure stress for unflawed vessels, ksi } \\
\kappa & =(3-4 \nu) \text { plane strain; }(3-\nu) /(1+\nu) \text { plane stress. }
\end{aligned}
$$

This relationship is basically the Griffith-Ir $\operatorname{win}^{11,12}$ flat-plate relationship that has been modified by the $(5 \pi / 32) \lambda^{2}$ term from Folias ${ }^{13}$ to include the effect of curvature (geometry), the $\cos \theta$ term from Dugdale ${ }^{14}$ to include the effect of plasticity at the tip of the notch or defect, and the $\kappa$ term from Swedlow ${ }^{15}$ to include the effect of the stress state (biaxiality and plane stress or plane strain).

The stress-intensity factor in Eq. 5.3, when defined for the critical stress at which point a defect has just become unstable and is starting to propagate, is commonly referred to as $\mathrm{K}_{\mathrm{c}}$ for the plane stress condition or $\mathrm{K}_{\mathrm{Ic}}$ for the plane strain condition.

Eq. 5.3 indicates that $\mathrm{K}$ is proportional to the nominal circumferential stress and the square root of the crack length. Thus, for a given matertal with a given $\mathrm{K}_{\mathrm{c}}$ or $\mathrm{K}_{\mathrm{Ic}}$ level, the longer the crack length, the lower the critical failure stress will be. Or in comparing two different materials in the same size vessel, the material with the highest $\mathrm{K}_{\mathrm{c}}$ or $\mathrm{K}_{\mathrm{Ic}}$ level is the toughest material; i.e., it will be able to tolerate longer defects without failure at a given stress level.

An experimental verification of the critical crack formulation is available from tests conducted at Battelle-Columbus on 30-in. diameter, 0.375 -in. wall steel pipe for the American Gas Association. ${ }^{17}$ Because of the high ductility of this steel, no valid* flat-plate tensile test results are available; however, full-scale pipe tests were conducted using throughwall defects. From the results of the first full-scale test a $\mathrm{K}_{\mathrm{c}}$ (plane stress value was calculated (approximately $300 \mathrm{ksi} \sqrt{\mathrm{in}}$.) from which the curve of

*Valid by the criterion established by the ASTM E-24 Committee, i.e., the net stress is less than 0.8 times the yield stress. 
failure stress vs critical crack length was developed。 Fig. 5.1 presents the calculated critical crack length-failure stress curve along with the actual full-scale data points for comparison. (The material is a plain carbon steel with a 60-ksi yield strength and an 80-ksi tensile strength.) It can be observed that there is good agreement between the calculated curve and the experimental data points.

On the basis of the results of tests on thin-walled pressure vessels, a hypothesis was formulated which allows the failure pressure of surface defects to be predicted if the $\mathrm{K}$ value is known. The following equation was formulated for predicting the failure stress of longitudinal surface defects in cylindrical vessels:

$$
\frac{\sigma_{\mathrm{fS}}}{\sigma_{\mathrm{C}}}=\frac{\mathbf{A}_{0}-\mathrm{A}}{\mathbf{A}_{0}-\mathbf{A}\left(\frac{\sigma_{\mathrm{ft}}}{\sigma_{\mathrm{c}}}\right)}
$$

where $\sigma_{\mathrm{fs}}=$ nominal failure stress for surface defect, ksi

$\sigma_{\mathrm{c}}=$ failure stress for unflawed vessels, $\mathrm{ksi}$

$\mathrm{c}=$ half of the crack length of surface defect, in.

$\mathrm{t}=$ thickness of vessel, in.

$A_{0}=2$ ct, area of through-wall defect of same length as surface defect, in.

$A=$ area of surface defect, in.

$\sigma_{\mathrm{ft}}=$ failure stress of through-wall defect of same length as surface defect, ksi (from Eq. 5.3).

The main uncertainty which has developed in the use of the above equations (5.3 and 5.4) is the value that should be used for $\sigma_{c}$, the failure stress for an unflawed vessel. Inconsistencies in the calculated $\mathrm{K}_{\mathrm{c}}$ values appeared with variations in crack length and in the wall thickness. In order to determine which value is the most appropriate, $\mathrm{K}_{\mathrm{c}}$ values were calculated for all through-wall tests using values of $\sigma_{\mathrm{c}}$ based on the ultimate strength, the yield strength, the biaxial yield strength, and combinations of the ultimate and yield strengths. The results indicate that the most consistent $\mathrm{K}_{\mathrm{c}}$ values are obtained by use of the average of the yield and ultimate strengths. 


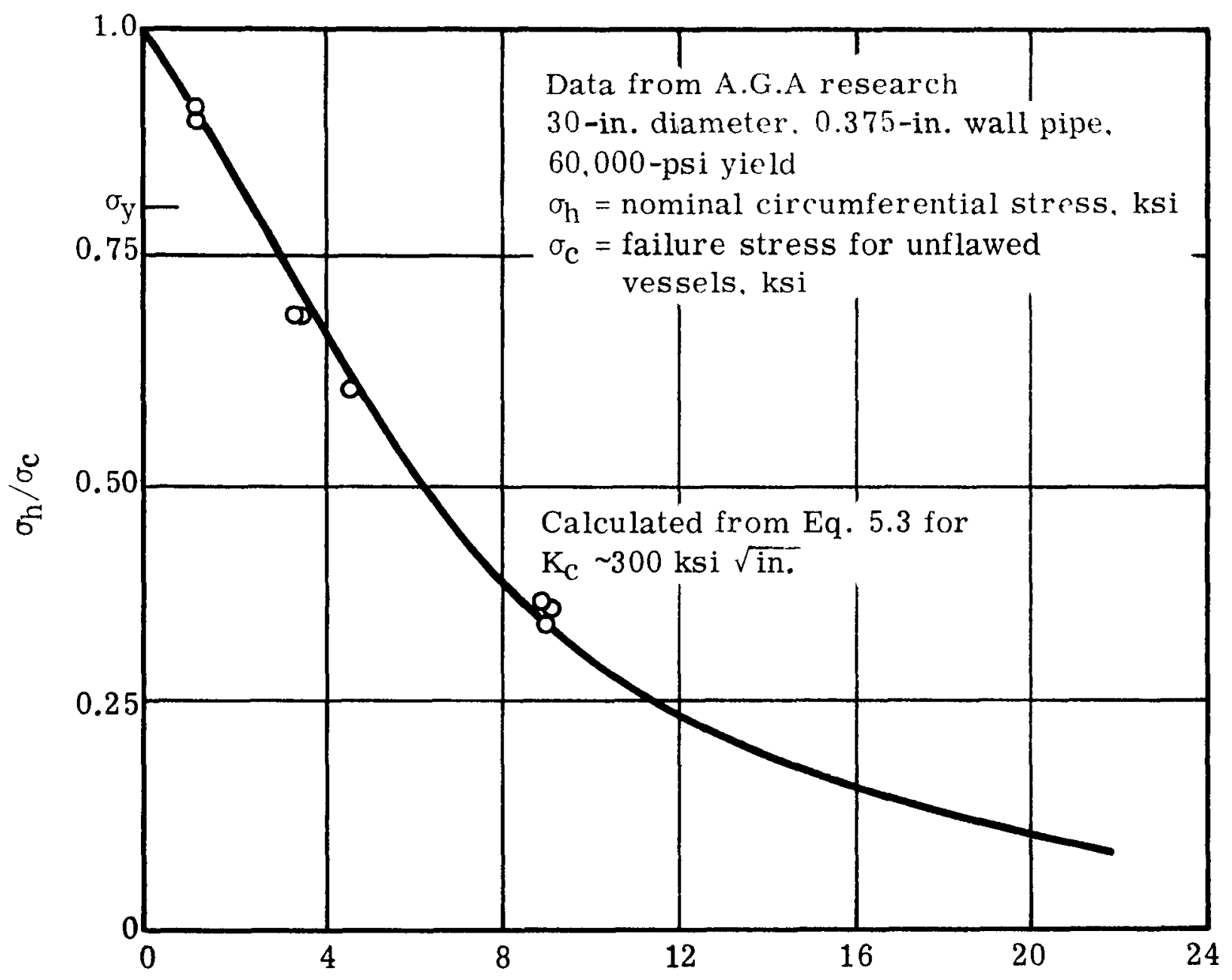

(2c) Crack Length, in.

Fig. 5.1 - Actual Relationship of Critical Crack Length and Failure Stress ${ }^{17}$ 
In an attempt to further resolve the inconsistencies, an alternative criterion has been proposed, as shown in Eqs. 5.5 and 5,6.

$$
\sigma_{\mathrm{f}}=\sigma_{1}^{\prime} 1+\frac{5 \pi}{32} \lambda^{2}
$$

or for Poisson's ratio $(\nu)=0.3$

$$
\sigma_{\mathrm{f}}=\sigma \sqrt{1+\frac{1.61 \mathrm{c}^{2}}{\mathrm{Rt}}}
$$

where $\lambda^{2}=\mathrm{c}^{2} / \mathrm{Rt} \sqrt{12\left(1-\nu^{2}\right)}$

$$
\begin{aligned}
\sigma_{\mathrm{f}} & =\text { flow stress of the material, ksi (may be used for } \sigma_{\mathrm{C}} \text { ) } \\
\sigma & =\text { nominal circumferential stress at failure, ksi } \\
\mathrm{C} & =\text { half crack length, in. } \\
\mathrm{R} & =\text { mean radius of pipe, in. } \\
\mathrm{t} & =\text { wall thickness, in. }
\end{aligned}
$$

To check the validity of the flow equation, the experimental data were substituted into the equation and $\sigma_{f}$ calculated for each test condition. This showed that the flow stress was relatively independent of crack length and wall thickness. A comparison of the calculated flow stress with the average of the uniaxial yield and tensile stress suggests that the flow stress may be closely approximated by the average of yield and ultimate stresses from a uniaxial tensile test of the material.

Calculated failure stress curves for the through-wall cracks compared well with the experimental data over the range of points investigated. Calculated failure stresses for the surface flaws predicted the failure stresses for the surface flaw experiments within approximately $10 \%$.

Further experimental work at BMI is expected to predict the behavior of flaws in other materials, particularly stainless steels, and to provide further verification of the proper value for $\sigma_{\mathrm{c}}$.

In general, for cracks or defects of the size and nature to be expected in LMFBR piping, failure by ductile rupture is not expected to be 
a controlling factor. Failure stresses would be of the order of 0.9 of the failure stress for unflawed cylinders. Therefore, fatigue or brittle fracture or other mechanisms probably would be the prime considerations, and these are covered in following sections. No special design requirements relating to ductile rupture are recommended for inclusion in the piping design guide.

However, in the event of specific conditions of design, fabrication, or materials properties, the preceding section provides a method of predicting the failure stress. A simple check should be made based on some known material properties to assure that the conditions are not such that ductile rupture may be a consideration. A simple chart might be provided in the LMFBR Piping Design Guide, based on geometry and one or more of the generally known material properties.

\subsubsection{Creep Rupture}

Present design practices to prevent failure by creep rupture are based on limiting the primary stress to some fraction of the stress that will produce a given creep strain rate, a limiting strain in $10^{5} \mathrm{hr}$, or rupture in $10^{5} \mathrm{hr}$. The concept of selecting values of allowable primary stress for use at high temperatures, based on experimental creep data, is both reasonable and practical from a design standpoint. Table 5. 1 contains a summary of current and suggested Code primary stress bases.

As discussed in Section 4, various formulations based on failure theories are required to predict rupture life under conditions of multiaxial stress from uniaxial rupture data. In Section 5.1.1 the problem in selecting the appropriate failure theory was indicated; namely, that some materials appear to satisfy the maximum principal stress criterion, while others appear to satisfy the distortion energy criterion. This area is under current study with the aim of selecting a failure theory appropriate for LMFBR materials, and consistent with other criteria recommendations made in this report.

Another factor of considerable importance to the prediction of creep rupture is the mathematical expression representing the material creep curve. From a practical standpoint, knowing that the design life of an LMFBR piping system is to be about 30 years, the method of predicting long-time behavior - that is, of extrapolating beyond the laboratory test period - must be considered. Several methods have been proposed, such as those based on constant-rate secondary creep (McVetty type), power functions, exponential functions, hyperbolic sine-function creep law (Nadai, Eyring), and others. It should be recognized that there may 
not exist sufficient experimental data to conclude that one method or another is necessarily the best for the general case.

The ASME Code Bodies faced similar problems in developing the boiler tube formula for application in the creep range. This formula considers the special case of multiaxial loading (2:1 ratio in pressureinduced stresses), and is of interest since it covers one of the stress states which will exist in LMFBR piping.

An evaluation of these problems and the conclusions resulting from their study will be documented in Technical Report 211.

Appendix A summarizes the historical events which led to the adoption of the present ASME Section I tube formula in the creep range. This area is currently under review by the ASME Subgroup on Elevated Temperature Design. While the committee has not completed its studies, these review efforts ${ }^{37}$ tend to support the use of a "mean diameter" formula:

$$
\mathrm{S}=\mathrm{P} \mathrm{D}_{\mathrm{m}} / 2 \mathrm{t}
$$

which is the hoop stress formula with the diameter $D_{m}$ taken at the middle surface of the tube. Other formulae which appear satisfactory are a full plasticity formula with uniform shear stress, and a membrane stress intensity formula. 
TABLE 5.1 - SUMMARY OF CODE PRIMARY STRESS BASES CURRENT AND SUGGESTED

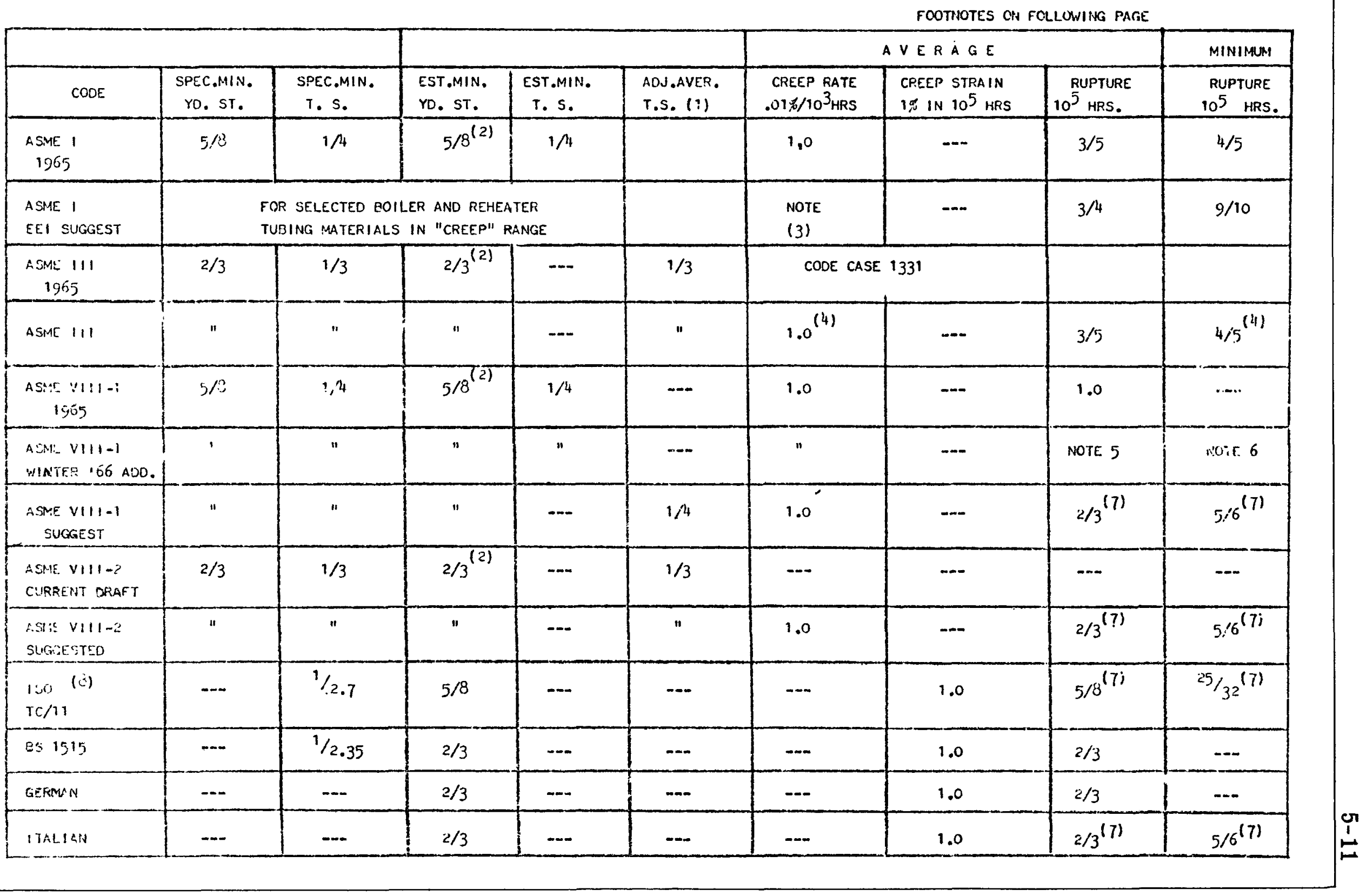




\section{FOOTNOTES FOR TABLE 5.1}

(1) Value resulting from increasing estimated minimum value by up to $10 \%$, providing that the adjusted average so derived does not exceed the arithmetic average of available data.

(2) $90 \%$ for austenitic stainless steels.

(3) $100 \%$ of average stress to produce secondary creep rate of $0.02 \%$ per $1000 \mathrm{hr}$.

(4) Plus deformation and life analysis when considered by designer to be desirable.

(5) Less than $60 \%$, "with a few exceptions."

(6) Some values up to $100 \%$.

(7) Value of average $10^{5} \mathrm{hr}$ rupture strength shall not exceed $5 / 4$ of minimum value.

(8) For temperatures below $250^{\circ} \mathrm{C}$, the stress for $250^{\circ} \mathrm{C}$ shall be used. 
In the case of LMFBR piping systems, the system may be operated for significant time intervals at conditions which are different from the normal operating conditions. A concept which may be used to evaluate the cumulative effect of a number of different temperature and/or stress conditions acting on the piping operating in the creep range is the rupture life expenditure. This direct approach, first given by Robinson, ${ }^{38}$ assumes that the temperature or stress conditions can be divided into steps at a fixed temperature and stress. For each of these steps, the creep rate or rupture life is obtained from conventional constant stress, constant temperature data. The total creep strain is assumed to be the sum of the strains occurring in the individual steps. Robinson also supposed that during any step of the temperature or stress cycle the stressed part loses some fraction of its total rupture life. This fraction depends only on the duration of the time step, the current stress, and current temperature, and is not affected by conditions before or after the steps. In a given step, the fraction of rupture life used up is the ratio (time step at the given stress and temperature)/(rupture life at the same given stress and temperature in a conventional rupture test). Rupture finally occurs when the sum of fractions equals unity. The validity of the above method for different materials was reviewed at an ASTM Symposium. $^{39}$ The data presented indicated that for many materials in their temperature range of usual interest, the predictions are satisfactory. However, satisfactory prediction is not to be expected if the higher ranges of temperature and stress are sufficient to produce structural changes in the material.

This approach is recommended for use in evaluating rupture life expenditure of LMFBR piping systems with the evaluation performed on the basis of primary membrane stresses. 
The life fraction rule is an application of the above concept which is being studied by the Subgroup on Elevated Temperature Design of the ASME Boiler and Pressure Vessel Code Committee. At present it is being considered only for boiler and pressure vessel tubes. Fig. 5.2 illus trates the use of the procedure for the specific case of utility boiler superheater tube ${ }^{40}$ for tubes under internal pressure, where the pressure is $P_{1}$ and the metal temperature is $T_{1}$ for $h_{1}$ hours, and is then changed to $\mathrm{P}_{2}$ and $\mathrm{T}_{2}$ for $\mathrm{h}_{2}$ hours.

\section{Nomenclature}

$$
\begin{aligned}
F & =\text { tube stress for each operating condition } \\
& =\frac{P(D-t)}{2 t}
\end{aligned}
$$




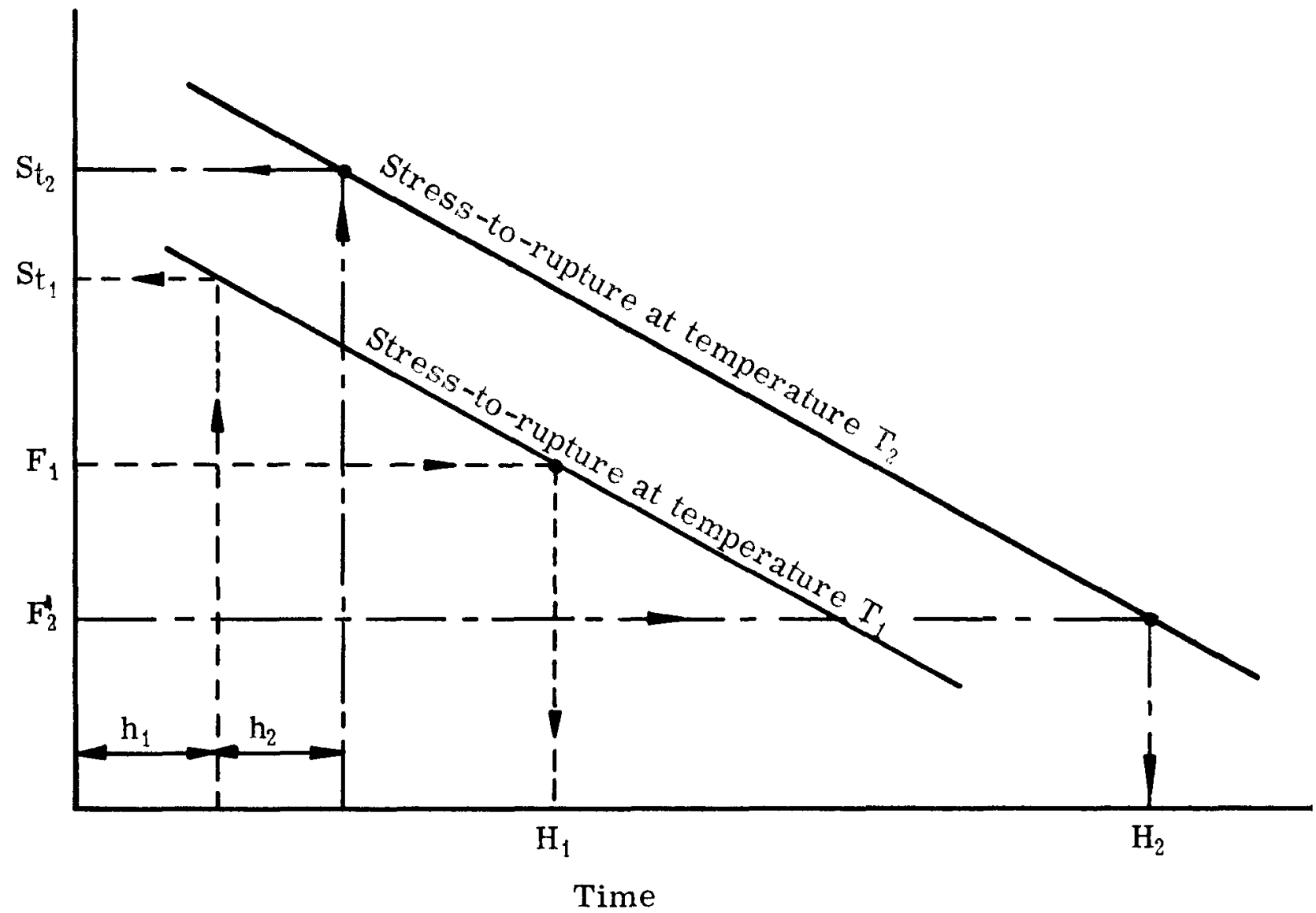

Fig. 5.2 - Illustration of Use of Life Fraction Rule 
$\mathbf{P}=$ pressure

$\mathrm{D}=$ outside diameter

$\mathrm{t}=$ wall thickness

$\mathrm{H}=$ time required for rupture at operating temperature and stress, hr

$\mathrm{h}=$ time at specific operating condition, $\mathrm{hr}$

$\mathrm{S}_{\mathrm{t}}=$ stress for rupture of tube, at each operating condition, using total accumulated operating time

$S_{R}=S_{t} / F=$ stress ratio for each operating condition; not to be less than 1.15

$E=$ life fraction for each operating condition, i.e., $E_{1}=h_{1} / H_{1}$, $\mathrm{E}_{2}=\mathrm{h}_{2} / \mathrm{H}_{2}$

$\mathrm{SE}=$ sum of all life fractions $(\mathrm{E})$ for operating conditions during the design life of the tube, i.e., $S E=E_{1}+E_{2}$

D. L. = design life of tube, i.e., $h_{1}+h_{2}, h r$

O.L. = operating life of tube in hours, i.e., O.L. $=(1-\mathrm{SE})\left(\mathrm{H}_{\mathrm{L}}\right)+$ D.L.

$\mathrm{H}_{\mathrm{L}}=$ rupture time for last operating condition (at lowest temperature and/or stress), hr

U. L. = use life of tube in years

$=\frac{\text { O.L. }- \text { D.L. }}{h_{L}}+$ D.L.E.

$h_{L}=$ operating hours per year for tube, after design life

D.L.E. = design life of equipment, i.e., boiler (during which design life of tube is accumulated).

The criterion for the evaluation of boiler tubes using the above method is that the use life (U.L.) is to be a minimum of $40 \mathrm{yr}$, based on a $28-y r$ boiler life (D. L.E.) during which time the tubes operate at temperature for $200,000 \mathrm{hr}$ (D. L.). It is assumed that after $28 \mathrm{yr}$, the tubes will continue to operate, at the last stress condition, for $5500 \mathrm{hr} /$ yr $\left(h_{L}\right)$. This could also be stated more generally by saying that the 
calculated operating life (O.L.) is to be at least 1.33 times as large as the required design life (D. L.).

An example showing how this is applied to the life evaluation of boiler tubes operating at one pressure, but at decreasing temperature levels, is given below. The calculations appear on the following page.

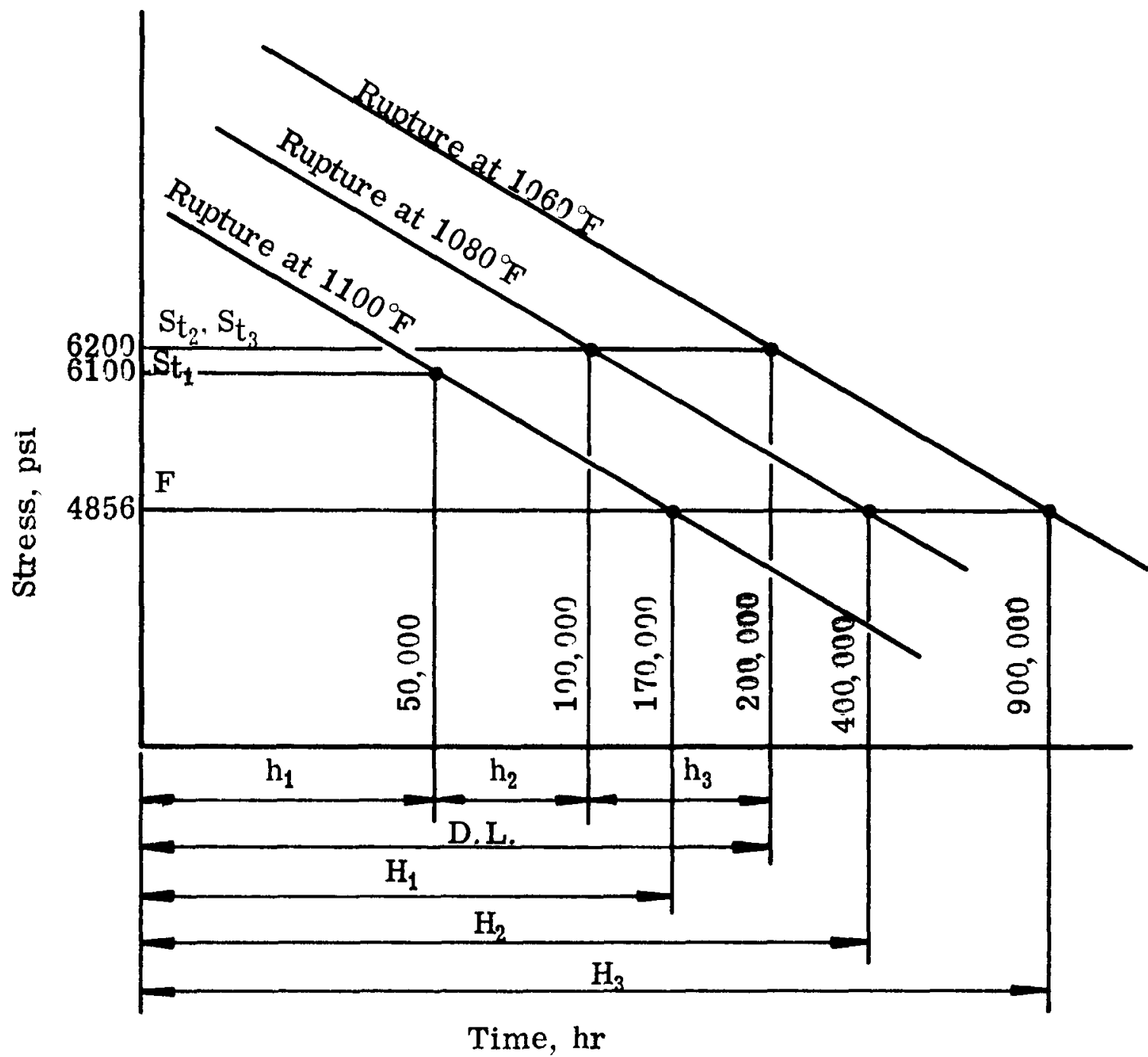

2 in. OD Tube $\times 0.556 \mathrm{MW}$ SA 213 T22 Material, Design Metal Temperature of $1100^{\circ} \mathrm{F}$ and Operating Pressure of 3740 psi. Tube Metal Temperature Reduced to $1080^{\circ} \mathrm{F}$ at the End of $50,000 \mathrm{hr}$ and to $1060^{\circ} \mathrm{F}$ at the End of $100,000 \mathrm{hr}$. 
$\mathrm{F}=\frac{\mathrm{P}(\mathrm{D}-\mathrm{T})}{2 \mathrm{~T}}-\frac{3740(2-0.556)}{1.112}=4856 \mathrm{psi}$

$\mathrm{SR}_{1}=\frac{\mathrm{S}_{\mathrm{t}_{1}}}{\mathrm{~F}}=\frac{6100}{4856}=1.256$

$\mathrm{SR}_{2}$ and $\mathrm{SR}_{3}=\frac{\mathrm{St}_{2}}{\mathrm{~F}}=\frac{6200}{4856}=1.277$

$\mathrm{E}_{1}=\frac{\mathrm{h}_{1}}{\mathrm{H}_{1}}=\frac{50,000}{170,000}=0.294$

$\mathrm{E}_{2}=\frac{\mathrm{h}_{2}}{\mathrm{H}_{2}}=\frac{50,000}{400,000}=0.125$

$\mathrm{E}_{3}=\frac{\mathrm{h}_{3}}{\mathrm{H}_{3}}=\frac{100,000}{900,000}=0.111$

$\mathrm{SE}=\mathrm{E}_{1}+\mathrm{E}_{2}+\mathrm{E}_{3}=0.294+0.125+0.111=0.530$

O.L. $=(1-\mathrm{SE})\left(\mathrm{H}_{\mathrm{L}}\right)+$ D.L. $=(1-0.530)(900,000)+200,000=623,000 \mathrm{hr}$

U. L. $=\frac{\text { O.L. }- \text { D.L. }}{\mathrm{h}_{\mathrm{L}}}+$ D.L.E. $=\frac{623,000-200,000}{5500}+28=104 \cdot 9 \mathrm{yr}$ 


\subsubsection{Excessive Gross Distortion}

Creep and plastic flow increase primary stresses but reduce secondary stresses. As discussed in Section 5.1.3, it is probably feasible to select values of allowable primary stress intensity limits for use at high temperature which are based on the creep strength (and/or rates). For many applications, allowable values of secondary stress still might be based on the yield strength at the operating temperature. However, for many situations, it is.necessary to perform detailed multiaxial elastic-plastic-creep analyses to determine the structural adequacy of the component for its intended design conditions. The remainder of this subsection reviews computational approaches for these situations.

A. Computational Procedures for Multiaxial Elastic-Plastic-Creep Analyses

When an LMFBR piping system is subjected to mechanical and thermal loads, as the load is applied, elastic and frequently plastic deformations take place practically instantaneously. With the passage of time, creep deformations occur, decreasing rapidly during the primary or transient phase of creep. When the steady or minimum rate of elongation is reached, the process is considered to be in the secondary phase of creep. Finally, in the tertiary phase of creep, elongations develop at an increasing rate until fracture occurs. These processes are illustrated in Fig. 5.3 for the case of uniaxial tensile loading.

The elastic strain is a consequence of changes in the lattice distance in the large number of crystals of which metals are composed, and is recoverable upon removal of the load. The mechanism of plastic deformation is the slip process in which the material slides along favorably oriented planes. Orowan ${ }^{47}$ considers the primary phase of creep also as a consequence of this slip process. On the other hand, he attributes the secondary creep to continuous deformation taking place in the noncrystalline layers that fill in the small gaps between crystals. These deformations are of a viscous type; as they take place, the adjacent crystals slide and roll. The instantaneous plastic deformation at time $t=0$ is nonrecoverable; both the primary and the secondary creep are nonrecoverable. 


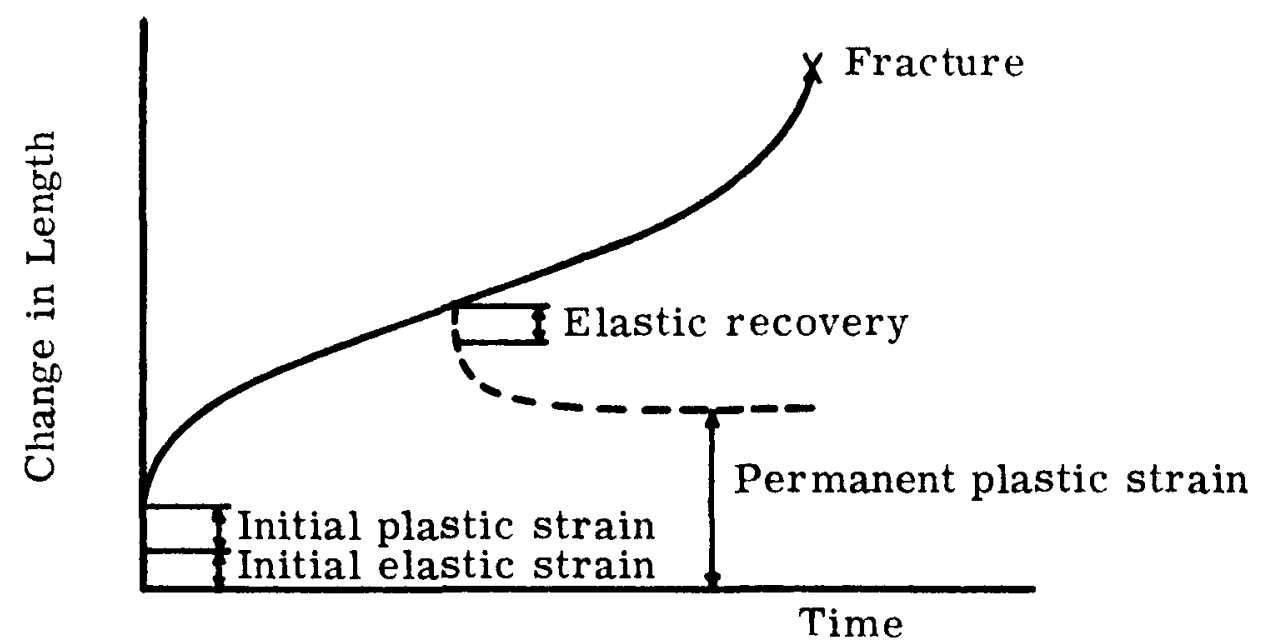

Fig. 5.3 - Illustrative Creep Curve for Uniaxial Tensile Loading - Dashed Line Shows Behavior on Unloading 
The basic differences between analyzing piping systems by linear thermoelastic methods, and analysis by methods which treat plastic flow or time-dependent creep, result from the nonlinear nature of the stress-strain relation. Total strains in a creep problem can be considered to be composed of an elastic strain and a strain due to creep. The same approach is applicable in plastic analysis where the total strains in the plastic regime are separable into an elastic strain and a nonlinear plastic strain. The creep problem is essentially a time-dependent cumulative plastic flow problem with additional postulations for the computations, namely, (1) the stress-strain-time (nonlinear) relations in the case of combined stress, and (2) the cumulativecreep laws in cases involving variable stress history.

In designing a piping system for LMFBR application, initial system evaluations could possibly be performed by linear thermoelastic analysis. Methods commonly used in the numerical analysis of multiaxial linear thermoelastic stress analysis include the method of finite differences, the finite element method, and the method of stepwise integration. The results of the linear thermoelastic studies would provide guidance for the more detailed plastic and creep analyses which may be required for critical joints and sections of an LMFBR piping system. In other words, regions identified in the linear elastic analysis to be in the plastic region, or potentially undergoing a significant amount of creep, would be subject to additional computations to deter mine the effects of creep and or plastic yielding. To assure accuracy and convergence in the results, a finer spatial mesh can be constructed in the structural model for the subsequent "regional" computations.

The usual procedure in creep problems is to divide the time into a large number of small time increments. These time increments are taken small enough such that the stress can be considered to be constant during the interval, and to increase as a step function at the end of the time interval. By considering the stresses constant during a particular interval, the changes in creep strains for that interval can be determined. Knowing the changes in the creep strains which occurred during the time interval, the changes in total strains then can be determined from equations developed from the conditions of equilibrium and compatibility. Finally, knowing the change in creep strain and total strain, the change in elastic strain and thus stress can be calculated. The resulting values of stresses are then held constant 
during the next time intervals, and so the procedure described above continues in a cyclic manner until the final time of operating life occurs. As the time intervals become infinitesimally small, the calculated stresses, strains, and deflections approach the exact solution for the assumptions involved.

The purpose of the following subsections is to summarize in sequential order the general computational procedures involved in performing an elastic-plastic-creep analysis. Fig. 5.4 is an illustrative flow diagram for this type of computation based on Incremental Theory.

\section{B. Elastic Analysis}

At time $\mathrm{t}=0$, determine: the total elastic stresses $\sigma_{\mathrm{r}}^{\prime}, \sigma_{\theta}^{\prime}, \sigma_{\mathrm{z}}^{\prime}$; the total effective elastic stresses $\sigma_{e}^{\prime}$; and the total effective strains $\epsilon_{\mathrm{e}}^{\prime}$. As shown in Fig. 5.4, the elastic analysis [corresponding to Steps (1) through (5)] is necessary for comparison with a yield criterion (flow rule) for subsequent plastic and creep analyses. This step in the analysis can be performed by any of the numerical methods for elastic analysis. Thus it can be seen that creep and plastic flow problems can be considered as extensions of existing elastic computation methods.

\section{Plastic Analysis}

The solution of plastic-flow problems involves the use of the same equilibrium and compatibility equations as elastic problems, ${ }^{35}$ but these equations must be combined with the nonlinear stress-strain relations instead of the linear Hooke's law. In previous discussion, we have es tablished that the difference between creep strain and plastic strain is that plastic strain is time-invariant, thus noncumulative. That is, unless the environmental (loading) condition during the operating life of the piping system changes, the plastic analysis can be considered to be the computations of plastic strains at time $t=0$.

Basically, there are two theories used in the formulation of the nonlinear stress-strain relation used in plastic analysis, namely, the Deformation Theory and the Incremental Theory. The deformation theory establishes a relation between the stresses and the total strains, so that, if the stresses are known, the strains can be directly established. The path by which a given stress distribution is reached presumably does not influence the strains. The incremental theory, on the other 


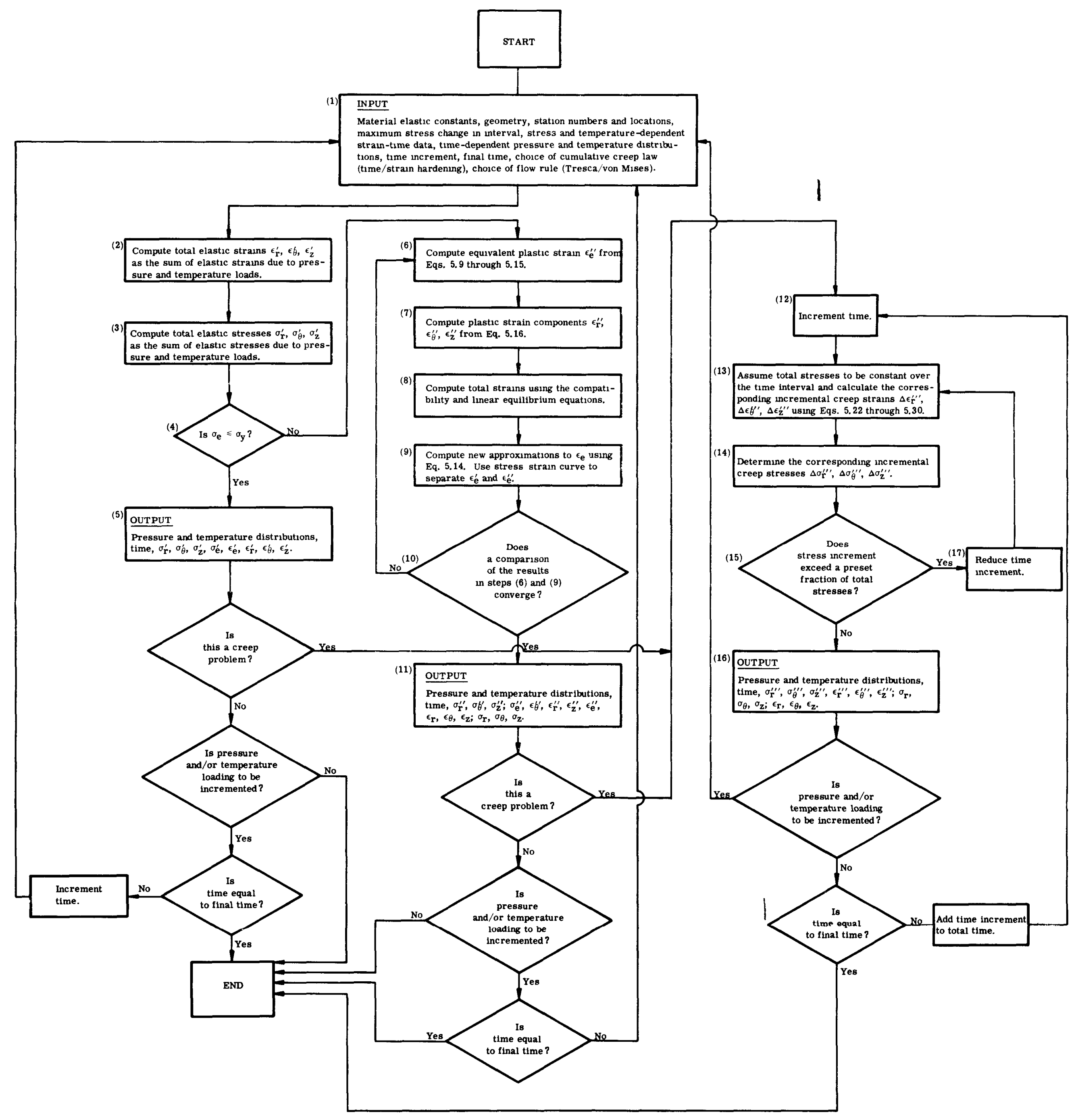

Fig. 5.4 - Schematic Flow Diagram - Computational Procectures for Multiaxial Thermoelastic-Plastic-Creep Stress-Strain Analysis 
hand, relates only the increment of strain to the increment of stress in a given stress state. To obtain the strain at a given stress state, the designer must consider the whole loading path - all the stress distributions that the body undergoes - adding up the increments of strain at each point to obtain the final strain. In numerical computations, the usage of incremental theory will require more computing time, but is more accurate ${ }^{35}$. The deformation theory may be useful in preliminary design when time is limited or when no computing machinery is available.

As discussed in Section 4, two "strength" theories, the maximum shear theory (Tresca), and the distortion energy theory (von Mises) have found acceptance for predicting the onset of plastic flow. For the maximum shear theory, the general yield criterion $c$ an be expressed as:

$$
\left|\sigma_{\mathrm{i}}-\sigma_{\mathrm{j}}\right|_{\max } \geqslant \sigma_{\mathrm{y}} \quad \begin{aligned}
& \mathrm{i}=1,2,3 \\
& \mathrm{j}=1,2,3
\end{aligned}
$$

For the distortion energy theory, the corresponding yield criterion can be expressed as:

$$
\left.\sqrt{1 / 2\left[\left(\sigma_{1}-\sigma_{2}\right)^{2}+\left(\sigma_{2}-\sigma_{3}\right)^{2}+\left(\sigma_{3}-\sigma_{1}\right)^{2}\right.}\right] \geqslant \sigma_{\mathrm{y}}
$$

Both flow rules are considered acceptable for engineering applications.

For illustrative purposes, the distortion energy approach will be used to describe the plastic analysis computational procedure. The governing stress-strain relations are as follows: ${ }^{35}$

1. The plastic shear strains are proportional to the shear stresses

$$
\frac{\epsilon_{\mathbf{r}}^{\prime \prime}-\epsilon_{\theta}^{\prime}}{\sigma_{\mathbf{r}}-\sigma_{\theta}}=\frac{\epsilon_{\mathrm{r}}^{\prime \prime}-\epsilon_{\mathrm{z}}^{\prime \prime}}{\sigma_{\mathrm{r}}-\sigma_{\mathbf{z}}}=\frac{\epsilon_{\theta}^{\prime \prime}-\epsilon_{\mathbf{z}}^{\prime \prime}}{\sigma_{\theta}-\sigma_{\mathrm{z}}}=\mathrm{constant}
$$

where $\sigma_{\mathrm{r}}, \sigma_{\theta}, \sigma_{\mathrm{Z}}=$ total stress components

$$
\epsilon_{\mathrm{r}}^{\prime \prime}, \epsilon_{\theta}^{\prime \prime}, \epsilon_{\mathrm{z}}^{\prime \prime}=\text { plastic strain (double primes denote plastic }
$$
components) 
2. The volume change due to plastic flow is zero.

$$
\epsilon_{\mathrm{r}}^{\prime \prime}+\epsilon_{\theta}^{\prime \prime}+\epsilon_{\mathrm{z}}^{\prime \prime}=0
$$

3. A universal relation exists between the equivalent stress $\sigma_{\mathrm{e}}$ and the equivalent plastic strain $\epsilon_{\mathrm{e}}^{\prime \prime}$. where

$$
\begin{aligned}
& \sigma_{\mathrm{e}} \equiv \frac{1}{\sqrt{2}} \sqrt{\left(\sigma_{\mathrm{r}}-\sigma_{\theta}\right)^{2}+\left(\sigma_{\mathrm{r}}-\sigma_{\mathrm{z}}\right)^{2}+\left(\sigma_{\theta}-\sigma_{\mathrm{z}}\right)^{2}} \\
& \epsilon_{\mathrm{e}}^{\prime \prime}=\frac{\sqrt{2}}{3} \sqrt{\left(\epsilon_{\mathrm{r}}^{\prime \prime}-\epsilon_{\theta}^{\prime \prime}\right)^{2}+\left(\epsilon_{\theta}^{\prime \prime}-\epsilon_{\mathrm{z}}^{\prime \prime}\right)^{2}+\left(\epsilon_{\mathrm{z}}^{\prime \prime}-\epsilon_{\mathrm{r}}^{\prime \prime}\right)^{2}}
\end{aligned}
$$

Furthermore, to separate the elastic and plastic components of strain, the concept of equivalent total strain, $\epsilon_{\mathrm{e}}$, is defined as follows:

$$
\epsilon_{\mathrm{e}} \equiv \frac{\sqrt{2}}{3} \sqrt{\left(\epsilon_{\mathrm{r}}-\epsilon_{\theta}\right)^{2}+\left(\epsilon_{\mathrm{r}}-\epsilon_{\mathrm{z}}\right)^{2}+\left(\epsilon_{\theta}-\epsilon_{\mathrm{z}}\right)^{2}}
$$

where $\epsilon_{\mathrm{r}}, \epsilon_{\theta}, \epsilon_{\mathrm{z}}=$ total strain components (including elastic, thermal, and plastic components).

We can readily determine the equivalent plastic strain $\epsilon_{\mathrm{e}}^{\prime \prime}$ by the following equation (derived by Mendelson and Mason). ${ }^{48}$

$$
\epsilon_{\mathrm{e}}=\epsilon_{\mathrm{e}}^{\prime \prime}+\frac{2(1+\mu) \sigma_{\mathrm{e}}}{3 \mathrm{E}}
$$

Now the relation between $\epsilon_{\mathrm{e}}^{\prime \prime}$ and $\sigma_{\mathrm{e}}$ is contained in the input data in the uniaxial stress-strain curve; hence, for any selected value of $\epsilon_{\mathrm{e}}^{\prime \prime}$, the value of $\sigma_{\mathrm{e}}$ can be determined. Once $\epsilon_{\mathrm{e}}$ has been computed by Eq. 5.14 and $\epsilon_{\mathrm{e}}^{\prime \prime}$ has been computed by Eq. 5.15 from the corresponding stress-strain curves, the components of plastic strain can be determined from the following equations. 


$$
\begin{aligned}
& \epsilon_{\mathrm{r}}^{\prime \prime}=\frac{1}{3} \frac{\epsilon_{\mathrm{e}}^{\prime \prime}}{\epsilon_{\mathrm{e}}}\left(2 \epsilon_{\mathrm{r}}-\epsilon_{\theta}-\epsilon_{\mathrm{z}}\right) \\
& \epsilon^{\prime \prime}=\frac{1}{3} \frac{\epsilon_{\mathrm{e}}^{\prime \prime}}{\epsilon_{\mathrm{e}}}\left(2 \epsilon_{\theta}-\epsilon_{\mathrm{z}}-\epsilon_{\mathrm{r}}\right) \\
& \epsilon_{\mathrm{z}}^{\prime \prime}=\frac{1}{3} \frac{\epsilon_{\mathrm{e}}^{\prime \prime}}{\epsilon_{\mathrm{e}}}\left(2 \epsilon_{\mathrm{z}}-\epsilon_{\mathrm{r}}-\epsilon_{\theta}\right)
\end{aligned}
$$

The above method of determining plastic strain components $\epsilon_{r}^{\prime \prime}, \epsilon_{\theta}^{\prime \prime}$, $\epsilon_{\mathrm{Z}}^{\prime \prime}$ from known values of total strain components is very useful in solving thermoelastic-plastic problems by successive approximation as follows:

1. Solve the equations, neglecting the nonlinear terms arising from the plastic flow. The result constitutes essentially the elastic solution, which is usually obtained as a starting point in any case.

2. Utilizing the strains (sometimes stresses) determined from the elastic solutions, together with the stress-strain curves, separate the elastic portion from the plastic.

3. Assume that the plastic strains so determined are correct, and substitute their numerical quantities into the original equations wherever nonlinear terms appear, thus converting all nonlinear terms to numerical quantities. Re-solve the remaining linear equation, obtaining new estimates for total strains.

4. Utilizing the newly determined total strains, again refer to the stress-strain curves and separate the elastic and plastic strains.

5. Compare the plastic strains so determined with the assumed values in the previous iteration. If they are not the same, repeat the procedure, utilizing the last-determined plastic strains as the estimates.

6. Repeat the process (iterate) until successive iterations produce no change in plastic strains at all locations. Obviously, 
beyond these points further iterations will simply repeat former ones; thus, since the assumed values yield identical resulting values, the equations are satisfied and the assumed values constitute the correct values.

The above steps correspond to Steps (6) through (9) in the flow diagram (Fig. 5.4).

\section{Creep Analysis*}

Creep problems may be solved in a manner similar to that of plasticflow problems. As previously discussed, plastic primary creep and secondary creep strains are nonrecoverable deformations. The differences between them are that creep deformations are time-dependent, obeying the cumulative creep laws, and strain starts to accumulate as time progresses from $t=0$ whether the structure is in elastic or plastic regimes.

In the theory of creep it is assumed that in a given increment of time the total strain increments are composed of an elastic part and a part due to creep, or

$$
\dot{\epsilon}_{i j}=\dot{\epsilon}_{i j}^{\prime}+\dot{\epsilon}_{i j}^{\prime \prime \prime} \quad i, j=1,2,3
$$

where the center dot denotes a time derivative and a single prime and triple primes refer to the elastic and creep components, respectively. Since the elastic strain rates are directly proportional to the stress rates by Hooke's law, we can also write

$$
\dot{\sigma}_{\mathrm{ij}}=\lambda \delta_{\mathrm{ij}} \dot{\epsilon}_{\mathrm{kk}}^{\prime}+2 \mathrm{G} \dot{\epsilon}_{\mathrm{ij}}^{\prime}
$$

where $\lambda, G$ are Lame's constants, and $\delta_{i j}$ is the Kronecker delta.

When thermal gradients $\mathrm{T}(\mathrm{r}, \theta, \mathrm{z})$ are present in the system in addition to the mechanical loads, the Duhamel method ${ }^{41}$ of thermal stress is utilized, in which body temperature gradients are replaced by internal body forces, surface temperatures by surface tractions, and internal temperature variation by a distributed internal pressure. We can expand Eq. 5.18 of $i, j=1,2,3$ corresponding to the cylindrical coordinates $(r, \theta, z)$ as follows:

*This section uses tensor notation in mathematical expressions. 


$$
\left.\begin{array}{l}
\sigma_{\theta}=\lambda\left(\epsilon_{\theta}+\epsilon_{\mathrm{r}}+\epsilon_{\mathrm{z}}\right)+2 \mathrm{G}\left(\epsilon_{\theta}-\epsilon_{\theta}^{\prime \prime \prime}\right)-\frac{\alpha \mathrm{ET}}{1-2 \nu} \\
\sigma_{\mathrm{z}}=\lambda\left(\epsilon_{\theta}+\epsilon_{\mathrm{r}}+\epsilon_{\mathrm{z}}\right)+2 \mathrm{G}\left(\epsilon_{\mathrm{z}}-\epsilon_{\mathrm{z}}^{\prime \prime \prime}\right)-\frac{\alpha \mathrm{ET}}{1-2 \nu} \\
\sigma_{\mathrm{r}}=\lambda\left(\epsilon_{\theta}+\epsilon_{\mathrm{r}}+\epsilon_{\mathrm{z}}\right)+2 \mathrm{G}\left(\epsilon_{\mathrm{r}}-\epsilon_{\mathrm{r}}^{\prime \prime \prime}\right)-\frac{\alpha \mathrm{ET}}{1-2 \nu}
\end{array}\right\}
$$

In Eq. 5.19, use is made of the fact that the dilatation rate in creep vanishes (same as the incompressibility of plastic strains):

$$
\epsilon_{\theta}^{\prime \prime \prime}+\epsilon_{\mathrm{z}}^{\prime \prime \prime}+\epsilon_{\mathrm{r}}^{\prime \prime \prime}=0
$$

Eqs. 5.19 and 5.20 can be combined to give more convenient expressions for $\sigma_{\theta}$ and $\sigma_{\mathrm{Z}}$.

$$
\begin{aligned}
& \sigma_{\theta}=\frac{\mathrm{E}}{\left(1-\nu^{2}\right)}\left[\epsilon_{\theta}+\nu \epsilon_{\mathrm{z}}-\left(\epsilon_{\theta}^{\prime \prime \prime}+\nu \epsilon_{\mathrm{z}}^{\prime \prime \prime}\right)-(1+\nu) \alpha \mathrm{T}+\frac{(1+\nu)}{\mathrm{E}} \quad \sigma_{\mathrm{r}}\right] \\
& \sigma_{\mathrm{z}}=\frac{\mathrm{E}}{\left(1-\nu^{2}\right)}\left[\epsilon_{\mathrm{z}}+\nu \epsilon_{\mathrm{z}}-\left(\epsilon_{\mathrm{z}}^{\prime \prime \prime}+\nu \epsilon_{\theta}^{\prime \prime \prime}\right)-(1+\nu) \alpha \mathrm{T}+\frac{(1+\nu)}{\mathrm{E}} \sigma_{\mathrm{r}}\right]
\end{aligned}
$$

Flow rules of some type must be used to obtain the triaxial creep rates from uniaxial creep data. The von Mises flow rule and the Tresca flow rule will be considered in this report. The von Mises flow rule is described by the following equations.

von Mises Flow Rule

$$
\begin{aligned}
& \dot{\epsilon}_{\theta}^{\prime \prime}=\frac{\dot{\epsilon}_{\mathrm{e}}^{\prime \prime \prime}\left(\sigma_{\mathrm{e}}, \epsilon_{\mathrm{e}}^{\prime \prime \prime}\right)}{\sigma_{\mathrm{e}}}\left(\sigma_{\theta}-\frac{\sigma_{\mathrm{z}}}{2}-\frac{\sigma_{\mathrm{r}}}{2}\right) \\
& \dot{\epsilon}_{\mathrm{z}}^{\prime \prime}=\frac{\dot{\epsilon}_{\mathrm{e}}^{\prime \prime}\left(\sigma_{\mathrm{e}}, \epsilon_{\mathrm{e}}^{\prime \prime \prime}\right)}{\sigma_{\mathrm{e}}}\left(\sigma_{\mathrm{z}}-\frac{\sigma_{\theta}}{2}-\frac{\sigma_{\mathrm{r}}}{2}\right) \\
& \dot{\epsilon}_{\mathrm{r}}^{\prime \prime}=-\dot{\epsilon}_{\theta}^{\prime \prime \prime}-\dot{\epsilon}_{\mathrm{z}}^{\prime \prime \prime}
\end{aligned}
$$


where

$$
\begin{aligned}
\sigma_{\mathrm{e}} & =\frac{1}{\sqrt{2}}\left[\left(\sigma_{\theta}-\sigma_{\mathrm{r}}\right)^{2}+\left(\sigma_{\mathrm{z}}-\sigma_{\mathrm{r}}\right)^{2}+\left(\sigma_{\theta}-\sigma_{\mathrm{z}}\right)^{2}\right]^{1 / 2} \\
& =\text { effective stress } \\
\epsilon_{\mathrm{e}}^{\prime \prime \prime} & =\frac{\sqrt{2}}{3}\left[\left(\epsilon_{\mathrm{r}}^{\prime \prime \prime}\right)^{2}+\left(\epsilon_{\theta}^{\prime \prime \prime}\right)^{2}+\left(\epsilon_{\mathrm{z}}^{\prime \prime \prime}\right)^{2}\right]^{1 / 2}=\text { effective creep strain } \\
\dot{\epsilon}_{\mathrm{e}}^{\prime \prime \prime} & =\mathrm{F}_{1}\left(\sigma_{\mathrm{e}}, \epsilon_{\mathrm{e}}^{\prime \prime \prime}\right) \text { (for strain-hardening rule) }
\end{aligned}
$$

or

$$
\dot{\epsilon}_{\mathrm{e}}^{\prime \prime \prime}=\mathrm{F}_{2}\left(\sigma_{\mathrm{e}}, \mathrm{t}\right) \text { (for time-hardening rule) }
$$

The equation of state has the form of Eq. 5.24 if the strain-hardening rule is used to obtain creep rates. If the time-hardening rule is used, then the equation of state has the form of Eq. 5.25. The functions $F_{1}$ and $\mathrm{F}_{2}$ are determined from uniaxial creep data.

When the Tresca flow rule is used, the equations are as follows:

\section{Tresca Flow Rule}

$$
\begin{aligned}
& \dot{\epsilon}_{1}^{\prime \prime \prime}=\frac{\dot{\epsilon}_{\mathrm{e}}^{\prime \prime \prime}}{\sigma_{\mathrm{e}}}\left(\sigma_{1}-\sigma_{3}\right) \\
& \dot{\epsilon}_{2}^{\prime \prime \prime}=0 \\
& \dot{\epsilon}_{3}^{\prime \prime \prime}=-\epsilon_{1}^{\prime \prime}
\end{aligned}
$$

where

$$
\begin{aligned}
& \sigma_{\mathrm{e}}=\sigma_{1}-\sigma_{3} \\
& \epsilon_{\mathrm{e}}^{\prime \prime \prime}=\frac{\epsilon_{1}^{\prime \prime \prime}-\epsilon_{2}^{\prime \prime \prime}}{2}
\end{aligned}
$$




$$
\dot{\epsilon}_{\mathrm{e}}^{\prime \prime \prime}=\mathrm{F}_{1}\left(\sigma_{\mathrm{e}}, \epsilon_{\mathrm{e}}^{\prime \prime \prime}\right) \text { (for strain-hardening rule) }
$$

or

$$
\dot{\epsilon}_{\mathrm{e}}^{\prime \prime \prime}=\mathrm{F}_{2}\left(\sigma_{\mathrm{e}}, \mathrm{t}\right) \text { (for time-hardening rule) }
$$

where

$$
\sigma_{1}>\sigma_{2}>\sigma_{3}
$$

The comments which applied to Eqs. 5.24 and 5.25 also apply to Eqs. 5.28 and 5.29. The stresses $\sigma_{1}, \sigma_{2}$, and $\sigma_{3}$ are equal to some order of $\sigma_{\mathbf{r}}, \sigma_{\mathbf{z}}$, and $\sigma_{\theta}$ where the exact order is determined at each point by relation (Eq. 5.30 ).

Eqs. 5.18 through 5.29 imply the solid is isotropic. The precise form of the cumulative creep law in each case of time-hardening creep law (Eqs. 5.25 and 5.29) or strain-hardening law (Eqs. 5.24 and 5.28) is obtained from uniaxial testing data. For example, if we assume for constant stress $\sigma_{e}$, the creep strain is given by

$$
\epsilon_{\mathrm{e}}^{\prime \prime \prime}=\mathrm{A} \sigma_{\mathrm{e}}^{\mathrm{n}} \mathrm{t}^{\mathrm{m}}
$$

then we can differentiate with respect to time to get expressions for the creep strain rate. If we differentiate directly, we obtain the socalled time-hardening creep law

$$
\dot{\epsilon}_{\mathrm{e}}^{\prime \prime \prime}=\mathrm{A} \sigma_{\mathrm{e}}^{\mathrm{n}} \mathrm{mt}^{\mathrm{m}-1}
$$

If, on the other hand, we take the $\mathrm{m}^{\text {th }}$ root of Eq. 5.31, before we differentiate with respect to time, then we obtain the so-called strain hardening creep law

$$
\dot{\epsilon}_{\mathrm{e}}^{\prime \prime \prime}=\mathrm{m} \mathrm{A}^{1 / \mathrm{m}} \sigma_{\mathrm{e}}^{\mathrm{n} / \mathrm{m}} \epsilon_{\mathrm{e}}^{\prime \prime \prime(1-1 / \mathrm{m})}
$$

Finnie and Heller ${ }^{42}$ indicate that while the strain-hardening law is more accurate than the time-hardening law, the latter presents fewer analytical difficulties. In the computation procedures described in Section 4, the computer code can be programmed to accept either law. 
Now, if we assume that the displacements are small enough to permit the use of the initial configuration as the equilibrium configuration, then we can obtain the equilibrium equations and the strain-rate velocity relations from available sources such as Kraus ${ }^{43}$ for thin shells and Sokolnikoff ${ }^{44}$ for three-dimensional solid bodies. In the general case we note, therefore, that in the absence of body forces and inertia effects the stress rates satisfy

$$
\dot{\sigma}_{i j, j}=0
$$

and the strain rates are related to the velocities $\dot{u}_{i}$ by

$$
\dot{\epsilon}_{i j}=\frac{1}{2}\left(\dot{u}_{i, j}+\dot{u}_{j, i}\right)
$$

With Eq. 5.10, the equilibrium equations take the form

$$
\lambda \delta_{i j} \dot{\epsilon}_{\mathrm{kk}, \mathrm{j}}+2 \mathrm{G} \dot{\epsilon}_{\mathrm{ij}, \mathrm{j}}=2 \mathrm{G} \dot{\epsilon}_{\mathrm{ij}, \mathrm{j}}^{\mathrm{c}}
$$

This completes the presentation of the field equations for a body undergoing creep. Their solution, once appropriate boundary conditions have been specified, can best be carried out in the general case with the digital computer.

The numerical computations for both primary (transient) and secondary (steady) creep are shown in Steps (12) through (17) in Fig. 5.4 in procedures as follows:

1. At time $t=0$, determine the elastic/plastic total stresses in the structural system by using either the finite difference method or the finite element method.

2. Assume that the stresses obtained at this time remain constant over a small increment of time $\Delta t$ and calculate the increments of creep strain that occur in the increment of time by use of creep laws and flow rules.

3. Use the creep strain increments thus obtained by solving the linear equations of equilibrium to compute the stress increments by the same numerical technique in elastic/plastic analysis. 
4. If the stress increments obtained in the previous step exceed a preset fraction of the existing stresses, repeat the previous processes with a smaller $\Delta t$. If the stress increments are less than the preset fraction of the existing stresses, determine the stresses at the end of the interval $\Delta t$ by adding the stress increments to the previous stresses in the body, that is,

$$
\sigma_{i j}(t+\Delta t)=\sigma_{i j}(t)+\Delta \sigma_{i j}(\Delta t)
$$

5. Add another time increment and repeat all previous processes, continue in this manner until the final desired time interval has been achieved.

\section{E. Ratchet Mechanisms (Incremental Distortion)}

As discussed in Section 3.1.4 excessive distortion may occur if the piping is subject to combinations of steady state and cyclic loads which produce incremental distortion or ratcheting. While the general multiaxial stress case of ratcheting in the presence of creep can be handled by the methods described in the preceding sections $A$ through $D$, it is pertinent to review the criteria for onset of ratcheting that can be developed from a simplified analytical model.

The pioneering paper on the thermal stress ratchet mechanism was written by Miller ${ }^{5}$ in 1959 . Since then, Miller's work has been expanded by Bree ${ }^{52,53,54}$ and Burgreen. ${ }^{55,56}$

The stress diagram of Figure 5.5 indicates the strain behavior of the material as a function of the loading conditions. Depending upon the stress regime, the material may undergo ratcheting, plastic cycling, shakedown, or purely elastic behavior.

Miller, using a one-dimensional elastic-perfectly-plastic model with the tensile and compressive yield stresses assumed equal, developed the following criteria for the onset of ratcheting. 


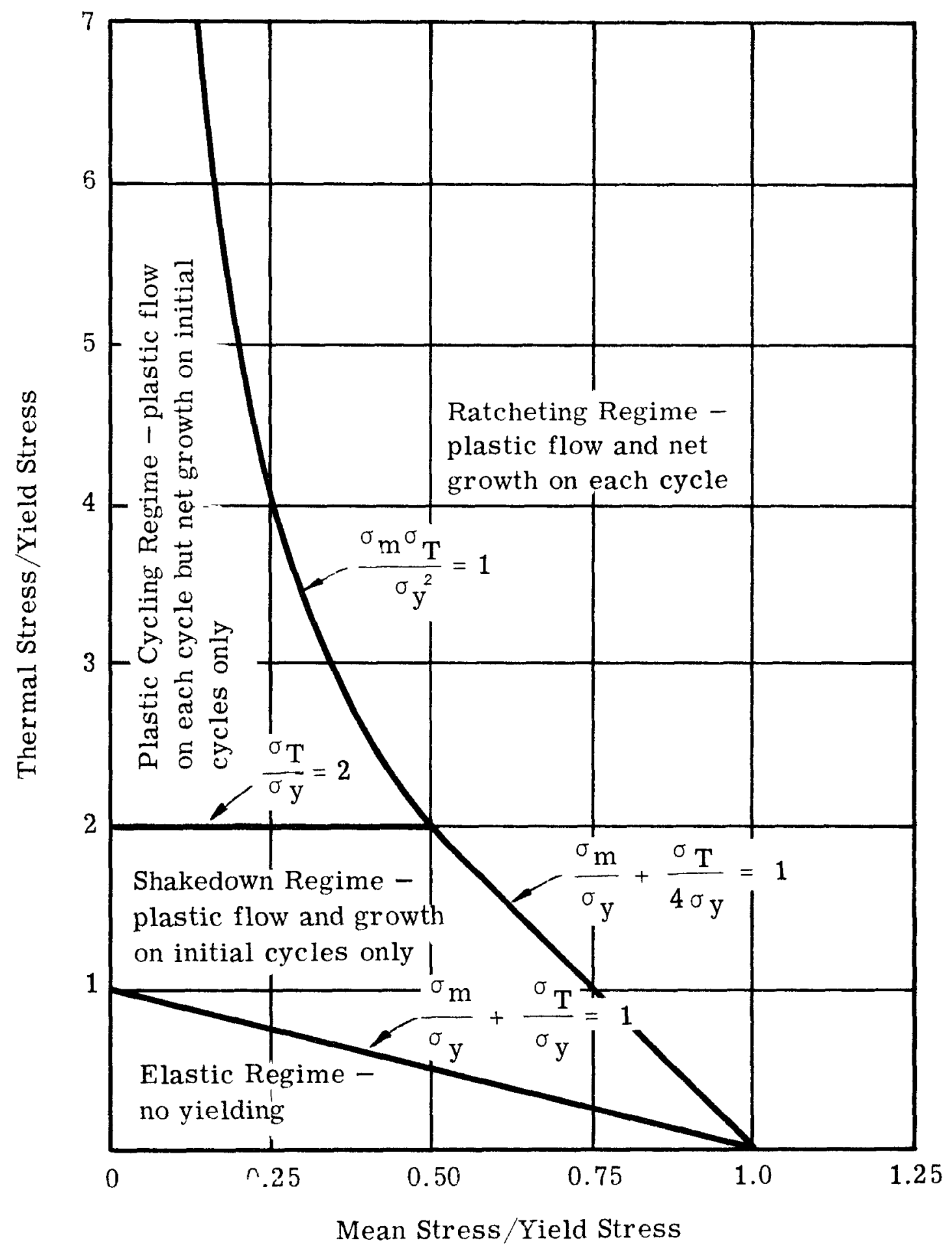

Fig. 5.5 - Uniaxial Stress Regimes - Mean Stress vs Thermal Stress Range for Linear Temperature Gradient 
For linear temperature variation through the thickness:

$$
\left.\begin{array}{ll}
\frac{\sigma_{\mathrm{m}}}{\sigma_{\mathrm{y}}}+\frac{\sigma_{\mathrm{T}}}{4 \sigma_{\mathrm{y}}}<1, & \text { when } \frac{\sigma_{\mathrm{m}}}{\sigma_{\mathrm{y}}}>\frac{1}{2} \\
\frac{\sigma_{\mathrm{m}} \sigma_{\mathrm{T}}}{\sigma_{\mathrm{y}}^{2}}<1, & \text { when } \frac{\sigma_{\mathrm{m}}}{\sigma_{\mathrm{y}}}<\frac{1}{2}
\end{array}\right\}
$$

While for plastic cycling,

$$
\frac{\sigma_{\mathrm{T}}}{\sigma_{\mathrm{y}}}>2, \quad \text { when } \frac{\sigma_{\mathrm{m}} \sigma_{\mathrm{T}}}{\sigma_{\mathrm{y}}^{2}}<1
$$

Similarly, for parabolic temperature variation through the thickness:

$$
\frac{\sigma_{\mathrm{T}}}{\left(5.2 \sigma_{\mathrm{y}}\right)}+\frac{\sigma_{\mathrm{m}}}{\sigma_{\mathrm{y}}}<1, \quad \text { when } \frac{\sigma_{\mathrm{m}}}{\sigma_{\mathrm{y}}}>0.615
$$

For

$$
\frac{\sigma_{\mathrm{m}}}{\sigma_{\mathrm{T}}}=0.3,0.4,0.5, \text { when } \frac{\sigma_{\mathrm{m}}}{\sigma_{\mathrm{y}}}<0.615 \text { then } \frac{\sigma_{\mathrm{T}}}{\sigma_{\mathrm{y}}}<4.65,3.55,2.70 .
$$<smiles>C1CCC2(CC1)CCCC2</smiles> 
where $\sigma_{\mathrm{y}}=$ yield stress

$\sigma_{\mathrm{T}}=$ maximum thermal stress calculated on an elastic basis.

$\sigma_{\mathrm{m}}=$ maximum membrane stress due to pressure.

Eqs. 5.38 and 5.39 are plotted in Fig. 5.5 to illustrate the various stress regimes discussed previously.

These criteria have been adopted by the ASME Boiler and Pressure Vessel Code, Nuclear Vessels (see Paragraph N-417.3), to define loading combinations where ratcheting might occur.

Miller developed the following relationships for the incremental growth per cycle for a thin-walled cylinder in the ratcheting regime.

For a linear temperature variation through the wall:

$$
\frac{\mathrm{y}}{\epsilon_{\mathrm{y}}}=2[\mathrm{~m}-2 \sqrt{\mathrm{m}(1-\mathrm{n})}](1-\nu)
$$

For a parabolic temperature variation through the wall:

$$
\begin{aligned}
& \frac{\mathrm{y}}{\epsilon_{\mathrm{y}}}=\frac{3 \mathrm{~m}(1-\nu)}{2}\left\{\left[\frac{1}{2}+\cos \left(\frac{\theta+4 \pi}{3}\right)\right]^{2}-\left(\frac{1-\mathrm{n}}{\mathrm{m}}\right)^{2 / 3}\right\} \\
& \theta=\cos ^{-1}\left[\frac{4}{\mathrm{~m}}(1-\mathrm{n})-1\right] .
\end{aligned}
$$

where $\mathrm{y}=$ growth per cycle

$$
\begin{aligned}
\epsilon_{\mathrm{y}} & =\mathrm{E} / \sigma_{\mathrm{y}} \\
\mathrm{m} & =\sigma_{\mathrm{T}} / \sigma_{\mathrm{y}} \\
\mathrm{n} & =\sigma_{\mathrm{m}} / \sigma_{\mathrm{y}} \\
\mathrm{E} & =\text { Young's modulus } \\
\nu & =\text { Poisson's ratio in the elastic range. }
\end{aligned}
$$

Since the general multiaxial stress case of ratcheting in the presence of creep can be handled by the methods delineated in the preceding sections A through $D$, based on recent work by Bree and Burgreen, it appears 
feasible to provide simplified methods or charts to estimate the incremental distortion for many of the multiaxial loading situations in the presence of creep anticipated in LMFBR piping. Development of these methods is recommended for incorporation into the final design guide.

\subsubsection{Elastic, Plastic, or Creep Instability}

As was indicated in Section 3.1.5, failure due to instability is one of the potential modes of failure of LMFBR piping systems. Separate tasks have been established within this project to study instability analysis methods (Task 240) and to establish instability analysis procedures (Task 415). Since approaches to predict the imminence of failure by instability are covered in Topical Report No. 240, they will not be repeated here. 


\subsection{BRITTLE FRACTURE}

\subsubsection{Fracture Analysis Diagram Approach}

One of the more recent practical approaches to fracture prevention is the transition temperature test method combined with fracture mechanics flaw size and stress factors, as described by Pellini and Puzak in Reference 18. The fracture analysis diagram was developed from concepts combining the best features of both of these approaches, and from this emerged the first practical, analytical method for the engineering design of fracture-safe structures.

The design method is based on a generalized stress-temperature diagram for fracture initiation and crack arrest. This diagram may be related to the service temperature by determination of one of several significant reference transition temperatures. A simple method for determining a reference transition temperature is provided by the dropweight test or by the Charpy $-\mathrm{V}$ test as correlated with the drop-weight test. This reference temperature is designated as the nil ductility transition temperature - NDT temperature. ${ }^{19,20}$

The significance of the NDT temperature may be brought out by discussion of the general effects of temperature on the fracture stress transition of steels (Fig. 5.6). A flaw-free steel is illustrated to develop a gradually increasing tensile strength (T.S.) and yield strength (Y.S.) with decreasing temperature; the increase in yield strength is greater than that of the tensile strength, resulting in coincidence at some very low temperature. At the temperature of coincidence, tensile ductility as measured by elongation or reduction of area (plastic flow) is decreased to essentially zero or nil value. This temperature may be considered as the NDT temperature in the absence of a flaw. If a small, sharp flaw is placed in the test specimen, such as a plate, a decreased level of fracture stress is obtained in the transition range as indicated by the dashed curve labeled "fracture stress decrease due to small, sharp flaw." The highest temperature at which the decreasing fracture stress for fracture initiation due to the small flaw becomes contiguous with the yield strength curve of the steel is defined as the nil ductility transition (NDT) temperature. Below the NDT temperature the fracture stress curve for the small flaw follows the course of the yield strength curve, as indicated by the continuation of the dashed curve to lower temperatures. The arrows 


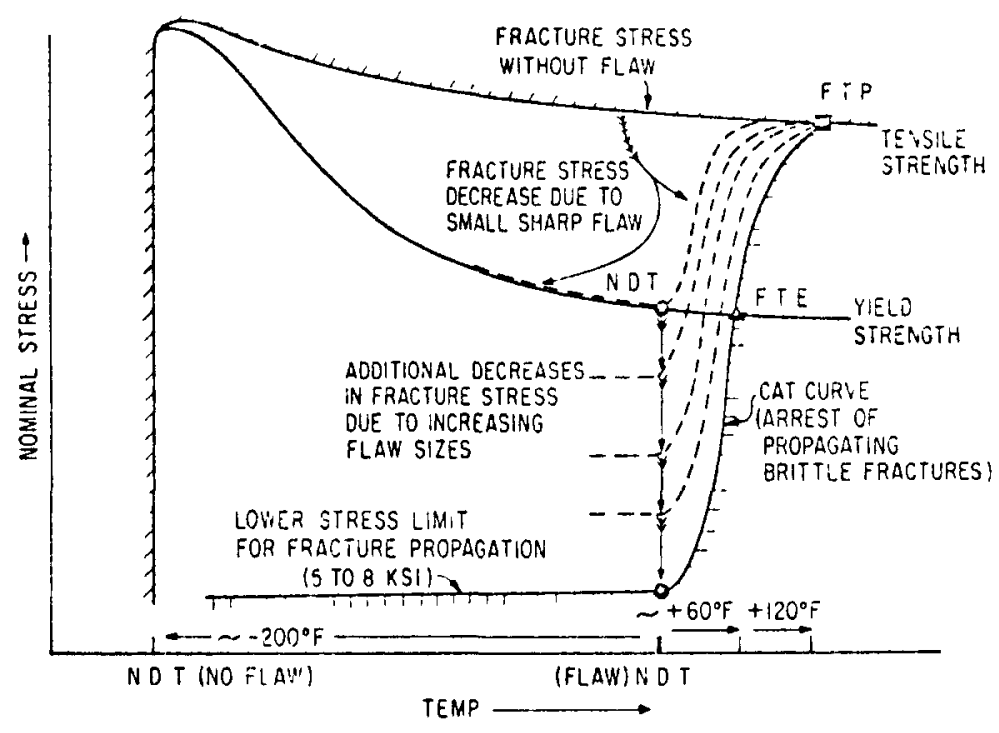

Fig. 5.6-Transition Temperature Features of Steels 
pointing down from the NDT point indicate that increases in the flaw size result in progressive lowering of the fracture stress curve to lower levels of nominal stress. As an approximation, the fracture stress is inversely proportional to the square root of the flaw size. The resulting family of fracture stress curves are characterized by a common temperature effect, involving a marked increase in the stress required for fracture as the temperature is increased above the NDT temperature.

A curve noted as CAT (crack arrest temperature) is drawn to represent the fracture arrest relationship between stress and temperature. The CAT curve represents the temperature of arrest of a propagating brittle fracture for various levels of applied nominal stress. The crack arrest temperature for a stress level equal to the yield strength has been defined by the authors in previous reports as the "fracture transition elastic" (FTE) temperature and marks the highest temperature of fracture propagation for purely elastic loads. Similarly, the "fracture transition plastic" (FTP) temperature has been defined as the temperature above which fractures are entirely shear, i.e., show no center regions of cleavage fracture, and the stress required for fracture approximates the tensile strength of the steel. The lower shelf in the range of 5 to $8 \mathrm{ksi}$, labeled as the "lower stress limit for fracture propagation," represents the stress level, below which fracture propagation is not possible because the minimum, small amount of elastic strain energy release required for continued propagation of brittle fractures is not attained.

The approximate range of flaw sizes required for fracture initiation at various levels of nominal stress have been incorporated with the temperature characteristics of the materials into a generalized fracture analysis diagram (FAD) as shown in Fig. 5. 7.

The flaw size data have been derived from a wide variety of small flaw tests, from limited studies of tensile tests with large flaws introduced into 1-in. and 3/4-in. thick plates, and from theoretical fracture mechanics concepts developed by G. R. Irwin. ${ }^{21}$ Validation is provided by a large amount of failure and structural test data to be presented. The generalized diagram presents a family of fracture initiation curves relating to a range of flaw sizes. These range from flaws of less than $1 \mathrm{in}$. (top dashed curve) to flaws in the order of 1 to $2 \mathrm{ft}$ (bottom dashed curve). It should be noted that all initiation curves have been drawn to 


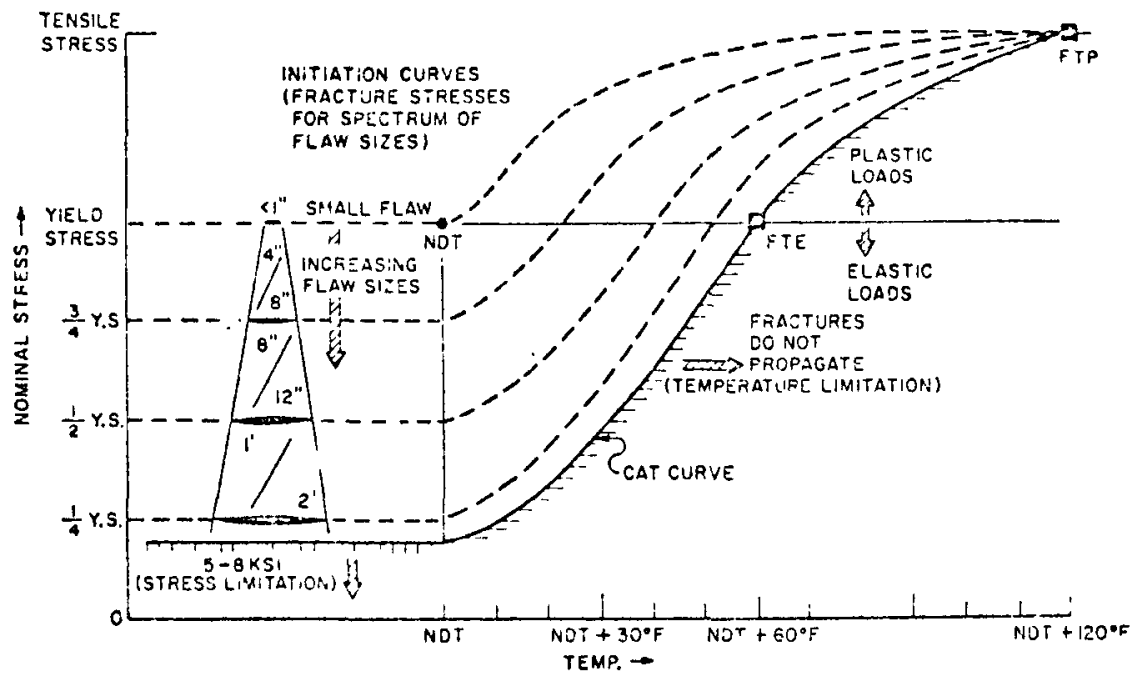

Fig. 5. 7 - Generalized Fracture Analysis Diagram, as Referenced by the NDT Temperature 
show a rapidly increasing requirement for higher stresses with increasing temperature above the NDT temperature. The actual slope and shape of the "rising" portions of the initiation curves represent estimates based on the general slope of the crack arrest curve.

The diagram predicts that for a given level of stress, larger flaw sizes will be required for fracture initiation above the NDT temperature. For example, at stresses in the order of $3 / 4$ yield strength, a flaw in the order of 8 to $10 \mathrm{in}$. may be sufficient to initiate fracture below the NDT temperature; however, at NDT $+30^{\circ} \mathrm{F}$, a flaw of $1 \frac{1}{2}$ to 2 times this size may be required for initiation. To the right of the CAT, there is "no flaw" that is of sufficient size to initiate fracture because propagation of brittle fractures is not possible. It should be noted that the nominal stress plotted in this diagram is the stress acting on the volume of material within which the flaw resides. Thus, for a flaw residing in the shell region of a pressure vessel, the nominal stress is the shell stress vector component; for a flaw residing at a nozzle, the nominal stress is the higher level of stress acting at that particular position in the nozzle.

The following are the general procedures which have been evolved for the fracture-safe design and engineering specification of steels based on the fracture analysis diagram.

The principal features of these procedures are illustrated in Fig. 5. 8. It is emphasized that the procedures apply to structures that contain flaws; if it is determined or assumed that the structure is flaw-free, there is no need for consideration of the fracture properties of steels! The basic fracture analysis diagram has four primary reference points which may be used as design criteria. These relate to the fabrication and design features of the structure with respect to the use or absence of stress relief, the expected level of stress at critical points (initiation points), the expected size of flaws at initiation points, the general level of stress, considerations of flaw size enlargement consequent to low cycle fatigue, etc. All of these are items requiring engineering design judgment. The four design criteria are defined as follows:

\section{NDT Temperature Design Criterion}

Service use above the NDT temperature is required for structures that are not thermally or mechanically stress relieved or that may be expected to develop points of local yielding, be- 


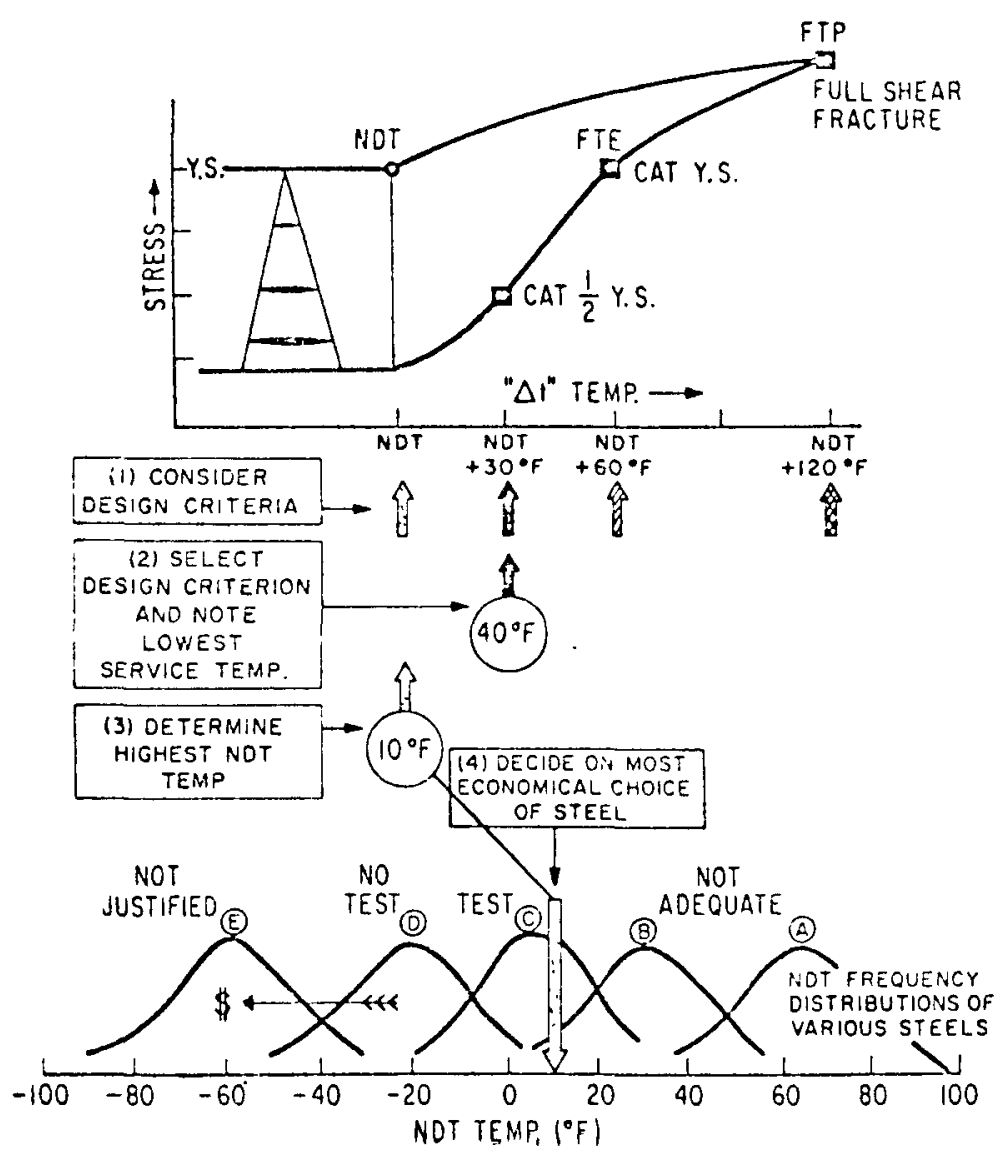

Fig. 5.8 - An Example Illustrating the Four Simple Steps for the Engineering Selection of Fracture-Safe Steels Based on the Fracture Analysis Diagram Concepts and a Catalog of NDT Data 
cause below the NDT temperature, very small flaws may serve as initiators under these conditions. Fracture protection is afforded by the rapid, stress-axis rise of the initiation curve for small flaws at temperatures above the NDT temperature.

2. NDT $+30^{\circ} \mathrm{F}$ Design Criterion

This design criterion relates to the CAT for stresses in the order of $1 / 2$ the yield strength of the steel. By restricting service use to above this temperature, the flaw-size evaluation problem disappears, provided the level of stress does not exceed $1 / 2$ the yield strength level, as is the usual case. In other words, since the fractures cannot initiate, they cannot propagate. This approach is inherent in the British engineering use of the isothermal Robertson CAT, the Esso use of the CAT for $18 \mathrm{ksi}$, and all other similar CAT methods.

\section{NDT $+60^{\circ} \mathrm{F}$ Design Criterion}

This design criterion is based on the same considerations as design criterion 2 above, except that the level of general stress is considered to be equal to the yield strength of the steel. This design criterion applied to the PVRC No. 1 vessel. It also applies to special cases involving high-test pressurization and reactor pressure vessel service conditions at nozzles due to severe thermal stress conditions.

\section{NDT $+120^{\circ} \mathrm{F}$ Design Criterion}

This design criterion is based on service requirements for plastic overload of the structure, which may involve either considerations of possible accidents or, as in the case of military structures, the expectation of explosive attack. The intent is to restrict service to full shear fracture temperatures in order to develop the utmost of fracture resistance.

Let us assume, for purposes of an example, that engineering judgment dictates the use of the NDT $+30^{\circ} \mathrm{F}$ (CAT) design criterion, and that $40^{\circ} \mathrm{F}$ represents the lowest expected service temperature. As noted in Fig. 5. 8, there are four simple steps of the analysis. 
1. The four design criteria, as noted on the diagram, are considered in relation to their significance with respect to the specific structure. The choice in this example is assumed to be the $\mathrm{NDT}+30^{\circ} \mathrm{F}$ (CAT) criterion.

2. The lowest service temperature, $40^{\circ} \mathrm{F}$ for the above-stated example, is related to the chosen design criterion.

3. The highest permissible NDT temperature then is determined from the $\Delta t$ scale of the diagram; this is $10^{\circ} \mathrm{F}$ for the abovestated case.

4. The most economical choice of steel is determined by the use of NDT data for the steels of interest, coupled with engineering judgment as to desirability of conducting selection tests, as described below.

Let us now assume that information is available as to the NDT frequency distribution curve of steels having the desired strength level and section thickness for the above case. Engineering judgment is then required regarding the most economical selection based on the availability of NDT frequency distribution data as illustrated at the bottom of the figure. The following considerations may apply:

Steels A and B - Not adequate because none of the A steels and only a very small part of the $B$ steel population may be expected to be suitable - test selection is not practical.

Steel C - Approximately $50 \%$ of the population should be adequate test selection is required.*

Steel D - All of the population should be adequate and no specification test is required for selection; however, it may be desirable to spot check for quality control reasons.

Steel E - Much lower transition temperature than is required; the added cost over Steel $\mathrm{C}$ is not justified.

*If it is decided to use the drop-weight test for specification purposes, for the above example, no-break performance ${ }^{19,20}$ would be required at the specification test temperature of $10^{\circ} \mathrm{F}$. This procedure does not require the determination of the NDT temperature; the no-break performance indicates that the (accepted) steel has an NDT that is below $10^{\circ} \mathrm{F}$. 
It should be apparent that the particular requirements of the job will determine the choice between Steels $C$ and $D$. The question of testing or not testing is a very practical one which relates to costs of pur chase on a test requirement basis as compared to the purchase of a more expensive steel that would not require testing.

For other design criteria (NDT, NDT $+60^{\circ} \mathrm{F}$, or NDT $+120^{\circ} \mathrm{F}$ ) than the illustrated example, similar procedures as described above are followed.

\subsubsection{Summary and Recommendations}

Since stresses of the order of the yield strength and above are anticipated at various locations in LMFBR piping systems, it is recommended that the design criterion to be used for LMFBR piping be NDT + $60^{\circ} \mathrm{F}$ as shown on the Fracture Analysis Diagram, Fig. 5.7. This basis insures that for stresses up to the level of the yield stress, no crack propagation will occur, and for stresses between the yield and ultimate stress, crack propagation will be arrested for defects below approximately 1-in. in length. Since this defect size seems to be a reasonable upper limit for undetected flaws in LMFBR piping systems, use of a design criterion of $\mathrm{NDT}+60^{\circ} \mathrm{F}$ would provide adequate safety against brittle fracture.

The usual methods of determining the ductile-brittle transition temperature (NDT) are by either the drop weight test (ASTM E-208) or the Charpy $-V$ notch impact test (ASTM A-370, Type A). Pellini ${ }^{1}$ discusses the unreliability of the Charpy-V test in establishing the NDT, and cites, as an example of unreliability, tests conducted on flasks fabricated from $2 \frac{1}{4} \% \mathrm{Cr}-1 \% \mathrm{Mo}, \mathrm{Q}$ and $\mathrm{T}$ steels. Although the $\mathrm{C}_{\mathrm{V}}$ shelfenergy values are in invariant correlation with the DT shelf-energy values, the temperatures at which the shelf is reached vary widely with the $\mathrm{C}_{\mathrm{V}}$ test. Therefore, for LMFBR piping it is recommended that the NDT determination be restricted to the drop weight test. 


\subsection{CRACK FORMATION AND PROPAGATION}

In previous sections the influence of cracks on failure due to ductile rupture and brittle fracture under steady loads was discussed. The influence of crack-like defects or other strain concentrations under cyclic loading conditions also requires evaluation.

There is now a fairly large body of data on fatigue at low temperatures (below the creep range) obtained from laboratory experiments under room-temperature conditions. ${ }^{35,57}$ The general procedure in such investigations is to control the strain between fixed limits, and if desired, to measure the stress, while cycling the specimen until failure is deter mined. Such tests may be under conditions of controlled diametral strain, longitudinal strain, bending strain, or torsional strain. The results can be represented in terms of total strain range vs cycles to failure, or, if desired, of plastic strain vs cycles to failure. The former is most often used for direct design procedures such as in Section III of the ASME Code, ${ }^{58}$ while the latter is applied when one is primarily interested in real material behavior. ${ }^{59}$

The high-temperature fatigue problem is in quite a different state. The material behavior becomes much more complicated at elevated temperatures because of the occurrence of creep and diffusion-controlled reactions.

It has been shown that frequency has a strong effect on fatigue properties. This is the same thing as saying that the strain rate is important, and related to this, the hold-time in the cycle is important, with fatigue life decreasing as hold-time increases.

Plastic strain, and in this case cyclic plastic strain, can have an important bearing on the precipitation of intermetallic phases and the strengthening effects which take place in the metal structure. This strain age hardening, while developing additional strength, also causes a reduction of ductility in the material. Since ductility is of prime consideration for fatigue resistance, this hardening effect, while increasing creep strength, reduces fatigue capabilities.

Another problem, applicable over the whole temperature range, is cumulative fatigue damage, where cyclic strains of greatly different magnitudes are experienced, and in a varying and probably random order 
of application. The order of application, as well as the difference in magnitude, may have a significant effect on the overall fatigue life.

\subsubsection{ASA Piping Code}

Probably the oldest code which considers fatigue and has limits on cyclic service is the ASA Piping Code which was developed in the early 1950's and adopted in 1955. This code has been used for more than 10 years, and so far, its use has yielded acceptable service life for piping. The allowable cyclic stress range for expansion stresses is given by the following equation:

$$
S_{A}=f\left(1.25 S_{c}+0.25 S_{h}\right)
$$

where $S_{A}=$ allowable stress range for expansion stresses

$\mathrm{S}_{\mathrm{C}}=$ basic material allowable stress at minimum (cold) temperature

$\mathrm{S}_{\mathrm{h}}=$ basic material allowable stress at maximum (hot) temperature

$f=$ stress-range reduction factor for total number of cycles.

\begin{tabular}{ll} 
Number of Cycles & $\mathrm{f}$ \\
\hline 7000 and less & 1.0 \\
7000 to 14,000 & 0.9 \\
14,000 to 22,000 & 0.8 \\
22,000 to 45,000 & 0.7 \\
45,000 to 100,000 & 0.6 \\
100,000 and over & 0.5
\end{tabular}

The basis for the above equation is outlined in Reference 60. It is based on a considerable number of cyclic tests on piping components at room temperature and also on an experimental loop alternately heated to $950^{\circ} \mathrm{F}$ and cooled to room temperature. Although the experimental work was with carbon steel, the results have been applied to other materials and temperatures on the basis of previous practice and acceptable service.

It has been estimated that in the range between 7000 and 250,000 cycles, the safety factor is in the order of 2 (stress) and 30 (cyclic life) on an average basis. The minimum value may be as low as 1.25 (stress) and 3 (cyclic life). When less than 7000 cycles are required, the safety factor increases because of the limit on the maximum stresses. 
This code has a number of shortcomings. It provides only for thermal expansion stresses as the cause of fatigue. There is no provision for the effect of corrosion, defects, or stress concentrations due to geometry on the fatigue life. No procedure is specified for the analysis of piping vibration or other cyclic mechanical loads. The damage from fatigue is cumulative, and the code lacks a procedure to evaluate this effect. The upper limit on stresses below 7000 cycles may impose severe limitations on some systems in which very few cycles are expected.

\subsubsection{ASME Code}

At the present time, only the ASME Code, Section III - Nuclear Vessels, requires a cyclic analysis for fatigue. The ASME Code, Section VIII, Division 2, and ASA Nuclear Piping Code,:B31.7, now issued for trial use and comment, have the same requirements. The Nuclear Vessel Code is based on an elastic behavior of the materials, and therefore, is limited at the present time to temperatures below the creep range. The high-temperature designs for nuclear construction may be made in accordance with Code Case 1331.

In Code Case 1331, the allowable stresses for cyclic conditions are given in curves of alternating stress, $S_{\mathrm{a}}$ (1/2 total stress range), vs number of cycles, as shown in Figs. 5.9 and 5.10. The effect of local strain concentration must be considered for each design detail. Where appropriate factors are not available, the design details must be proved by analysis or by test. The cumulative damage factors are added linearly for various stress cycles.

While this procedure is satisfactory for most lower-temperature fatigue analysis, there is no experimental verification in the high-temperature range. Cumulative damage may occur at a faster rate than the linear summation would indicate in the high-temperature range.

To establish the above fatigue curves, considerable data were supplied by sources listed in Reference 60 . This information was obtained from high-temperature strain-cycling fatigue tests under both axial and bending loading conditions. Materials were primarily $2 \frac{1}{4} \mathrm{Cr}-1 \mathrm{Mo}$ and Type 304 stainless steel. The equivalent alternating stress intensity was obtained by multiplying the strain range by $\mathrm{E} / 2$ for the test temperature. A safety factor of 2 on stress level and 20 on cycles was applied to the fatiguefailure curve to obtain the design curve. However, for the high-temperature 


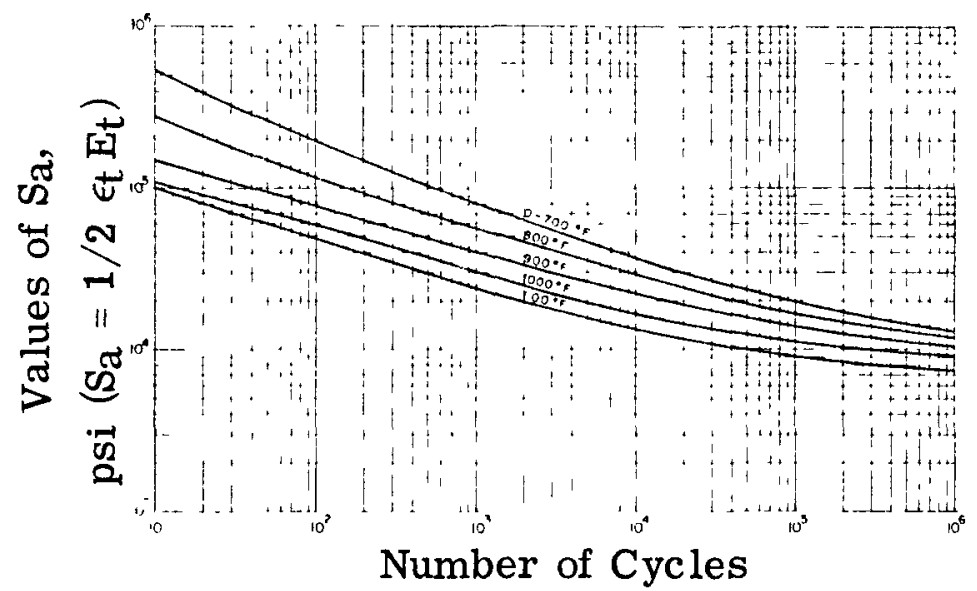

Fig. 5.9 - Design Fatigue Strength, Sa, for Carbon and Low-Alloy Steels through $5 \% \mathrm{Cr}$ up to $1100^{\circ} \mathrm{F}$ 


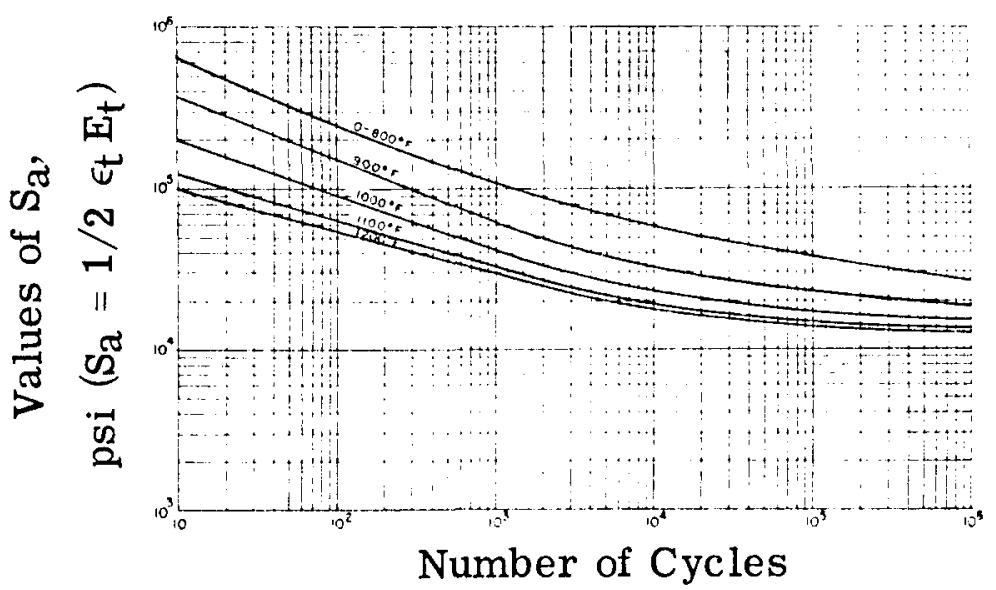

Fig. 5.10 - Design Fatigue Strength, $\mathrm{S}_{\mathbf{a}}$, for High-Alloy Steels and Nickel-Chrome-Iron Alloy up to $1200^{\circ} \mathrm{F}$ 
curves the failure curve to which the safety factor was applied was a minimum curve derived from the test data, instead of the average, because of the small amount of data available.

The following additional adaptations were made in determining the final design stress values.

In the very low-cycle region it is difficult to compare typical service cycles with test results. Since some operational upset is usually the reason for a cyclic condition of very few cycles, the actual time involved is usually a very small fraction of the total time. To make some allowances for stress-rupture effects and possible shortcomings in calculating the plastic strains, the allowable value for 10 cycles was obtained by taking a mean of the value derived from the short-time, hightemperature fatigue test and an extrapolated value from the ASA Piping Code. For carbon and low-alloy steel materials, which are known to suffer embrittlement from long temperature exposure, the values were further reduced on the basis of engineering judgment.

In the high-cycle region $\left(10^{6}\right.$ cycles) a different problem exists in the development of a design curve. The influence of mean stress needs to be considered. A design curve could have been developed with an analytical procedure for making the necessary corrections ${ }^{58}$ when mean stress is present. However, in the interest of simplicity and a conservative code basis, the mean stress correction was incorporated into the design curve. Although tests show that mean stresses do decrease under cyclic straining, they do have a pronounced effect on the total creep strain. The effect on cyclic life is particularly noticeable on those alloys which have a substantially higher yield strength than endurance limit.

In the intermediate cycle region $\left(10^{3}\right.$ to $10^{6}$ cycles $)$ the curves were developed from the high-temperature strain fatigue data as indicated above. From the limited data available, a minimum trend curve was constructed as a basis for determining the design curve. Some fair ing in and lowering of the ends of this curve were necessary to match the high- and low-cycle regions.

One of the greatest deficiencies of the above code design procedure is that no provision is made for evaluating the effect of hold-time or strain rate on the cyclic life for a given loading condition. The provi- 
sion for a linear cumulative damage rule is not satisfactory for all conditions since it is known that for loads of different magnitude, the order of their application can have a significant effect on the fatigue life. The code also does not provide values for strain concentrations due to defects or other discontinuities, although it gives procedures for obtaining them. Since practically all of the data incorporated into the fatigue curves in Code Case 1331 are for materials other than carbon steel, it is felt that these stress values should not be applied to carbon steels at elevated temperatures (above $900^{\circ} \mathrm{F}$ ). There are other factors which still require evaluation, some of which are: the effect of the observed loss of ductility in long time stress-rupture tests, the difference between thermally induced fatigue strength and mechanically induced fatigue strength for the same strain amplitude and equivalent temperature, and the nonlinear behavior of creep under programmed loading.

There are a number of investigations ${ }^{60}$ being made into the above problems under the sponsorship of such organizations as the PVRC, ASME, and ASTM, and by various industrial organizations. The aim of these investigations is to develop basic material properties for design and to develop methods to evaluate the significance of the nonlinear interactions between creep, stress rupture, fatigue, and metallurgical transformations.

However, it is not expected that there will be any major changes in the provisions of the Codes in the near future. Code Case 1331 is in the process of being revised by the ASME Subgroup on Elevated Temperature Properties to represent each material individually with the stress range, $\mathrm{S}_{\mathrm{a}}$, adjusted in the ratio of modulus of elasticity, $\mathrm{E}$, and the upper temperature limits on carbon steel reduced.

\subsubsection{Approximate Methods of High-Temperature Fatigue Evaluation}

Coffin ${ }^{59}$ has developed an expression for fatigue life in terms of plastic strain and fatigue ductility. The fatigue ductility is defined as:

$$
\epsilon_{\mathrm{f}}^{\prime}=2 \mathrm{~N}_{\mathrm{f}}^{1 / 2} \Delta \epsilon_{\mathrm{p}}
$$

where $N_{f}=$ number of cycles to failure

$\Delta \epsilon_{\mathrm{p}}=$ plastic strain range. 
The fatigue ductility, $\epsilon_{\mathrm{f}}^{\prime}$, can be obtained from a fatigue test, and it also has been shown that it can be correlated with the tensile ductility, $\epsilon_{\mathrm{f}}$, obtained from a uniaxial tensile test. The tensile ductility is defined as $\ln A_{0} / A_{f}$, where $A_{0}$ and $A_{f}$ are the initial and final areas of the fracture cross section in the tensile test. This value is assumed to equal the fatigue ductility at $1 / 4$ cycle, treating the tensile test as $1 / 4$ of a complete strain cycle.

Since the strain rate is an important variable at higher temperatures, this effect has been taken into account by rewriting Eq. 5.43 into the form:

$$
\mathrm{N}_{\mathrm{f}}^{1 / 2} \frac{\Delta \epsilon_{\mathrm{p}}}{\epsilon_{\mathrm{f}}^{\prime}}=\frac{1}{2}
$$

and plotting $\Delta \epsilon_{\mathrm{p}} / \epsilon_{\mathrm{f}}^{\prime}$ vs $\mathrm{N}_{\mathrm{f}}$. An example of this type of plot is shown in Fig. 5. 11.

Since elevated-temperature low-cycle fatigue appears to bear some relation to fracture ductility, and since both temperature and strain rate are involved, another parameter has been introduced to account for temperature and strain rate. Letting the parameter, $P$, be of the form

$$
\mathrm{P}=\mathrm{T} /\left(\mathrm{C}-\log \dot{\epsilon}_{\mathrm{p}}\right)
$$

the variation of this parameter with both fatigue and fracture ductility has been compared, using data from tests covering a wide range of temperatures and strain rates. Although there is scatter, there appears to be a generally well-defined relationship of decreasing ductility with increasing temperature. With a plot of fatigue ductility vs the above parameter for a given material, when temperature and strain rate are known the fatigue ductility can be obtained directly from the curve, without requiring test data for the specific strain rate and temperature conditions. A plot of plastic strain range vs cycles to failure based on different values of the above parameter is illustrated in Fig. 5. 12.

In summary, because both temperature and strain rate are important variables in high-temperature low-cycle fatigue, the low-tem- 


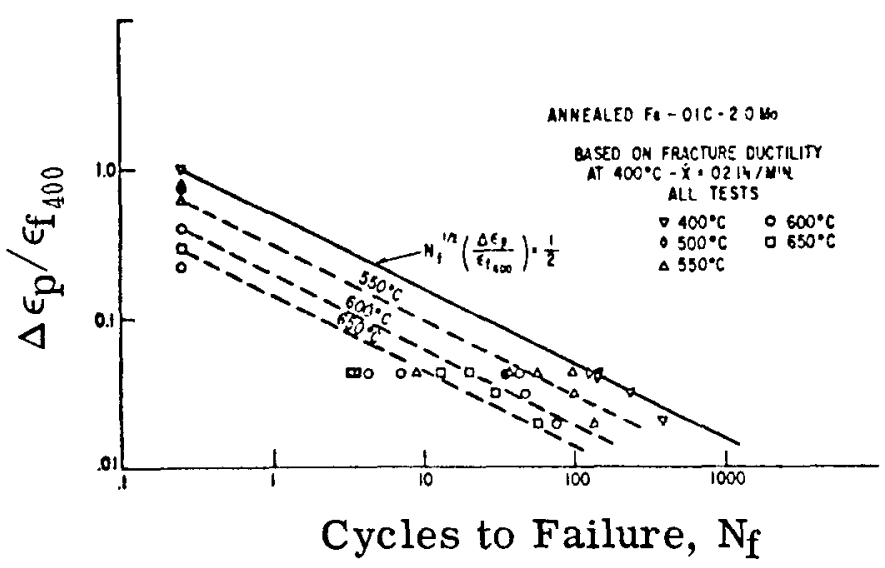

Fig. 5.11 - Plastic-Strain Range vs Cycles to Failure for Annealed Fe-0.1\% C-2.0\% Mo, Based on Fracture Ductility at $400^{\circ} \mathrm{C}$ 


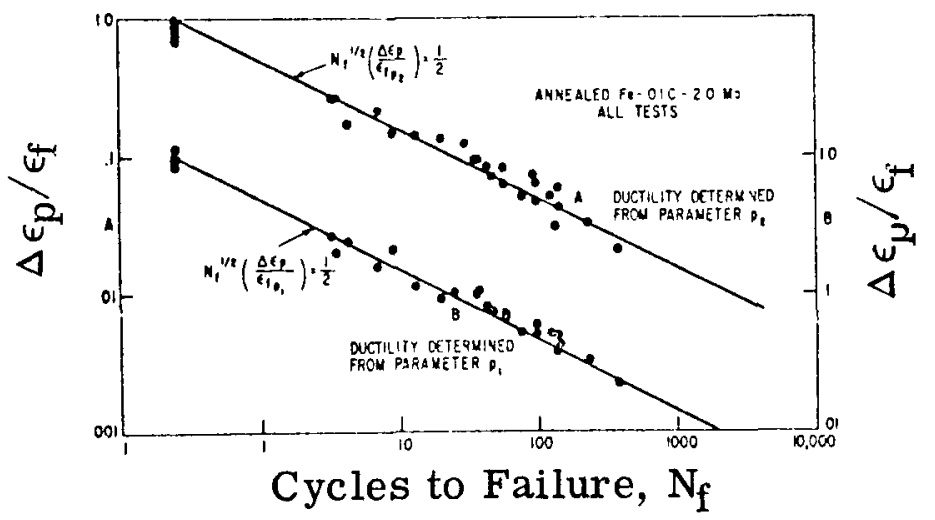

Fig. 5. 12-Ductility Normalized Plastic-Strain Range vs Cycles to Failure for Annealed Fe-0.1\% C-2.0\% Mo Steel 
perature fatigue equation cannot be used in the form given by Eq. 5.43. However, it is shown, for a limited number of cases, that fracture ductility can be used to predict fatigue behavior provided that ductility was obtained at the same temperature and strain rate as the fatigue test. This requires experimental complexity such that these procedures are not generally followed today.

Manson ${ }^{61}$ has presented a procedure for estimating the high-temperature reversed-strain cycling fatigue characteristics of laboratory specimens with reasonable accuracy from a knowledge of the static tensile and creep rupture properties at the temperature involved.

At room temperature, it has been found that the fully reversedstrain-cycling fatigue characteristics of materials can be estimated by considering their tensile properties as measured in a monotonic tensile test - namely the ultimate tensile strength, the ductility, and the elastic modulus. Room temperature, in these cases, is a temperature well below the creep range of the materials, or less than about half the absolute temperature at the melting point. Fig. 5.13 illustrates the "'method of universal slopes." The total strain range is divided into its elastic and plastic components, and each component is plotted against cyclic life on $\log -\log$ coordinates. Straight lines usually result for each of these components. The method of "universal slopes" prescribes that the slopes of these lines are assumed to be the same for all materials. The plastic components are taken to have an average slope value of -0.6 , and the elastic components an average slope value of -0.12 . Again, it should be emphasized that these values are not always -0.6 and -0.12 for all materials; values between -0.4 and -0.8 have been obtained for various materials for the plastic component, and values between -0.08 and -0.16 have been found for the elastic components. When average values of -0.6 and -0.12 are chosen for the plastic and elastic components, reasonable results are obtained.

Having decided on the slopes, it is then only necessary to determine the intercepts of the two straight lines. In general, it has been found that the property which most significantly governs the intercept of the plastic line is the ductility $D$. [ $D=\ln 100 /(100-R A)$, where $\mathrm{RA}$ is the percent reduction of area in the tensile test.] For the elastic line, the governing property for the intercept is $\sigma_{\mathrm{u}} / \mathrm{E}$, where $\sigma_{\mathrm{u}}$ is the ultimate tensile strength and $\mathrm{E}$ the elastic modulus. The total- 


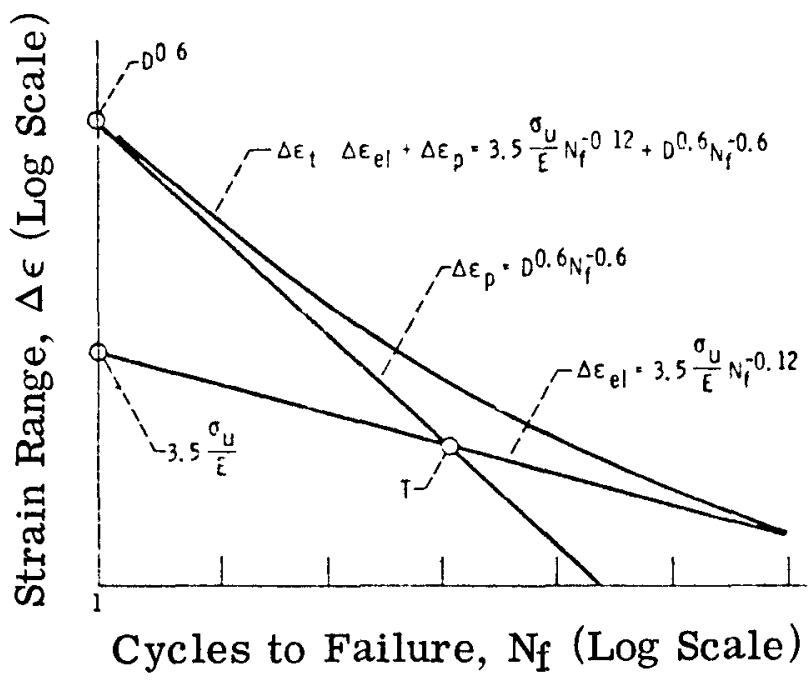

Fig. 5.13-Method of Universal Slopes for Estimating Axial Fatigue Life 
strain range, given as the sum of the elastic and plastic components, thus becomes

$$
\Delta \epsilon_{\mathrm{t}}=\frac{3.5 \sigma_{\mathrm{u}}}{\mathrm{E}}\left(\mathrm{N}_{\mathrm{f}}\right)^{-0.12}+\mathrm{D}^{0.6}\left(\mathrm{~N}_{\mathrm{f}}\right)^{-0.6}
$$

as shown in Fig. 5. 13.

The success of this approach applied to a number of materials is indicated in Reference 61 where the data for nine high-strength materials are presented together with the predictions based on the method of universal slopes. Correspondingly good agreement has been obtained for other materials.

Investigation has shown that for high-temperature fatigue the above approximation almost always yields life predictions higher than those actually obtained by testing. In a continuing study, it was found that in the creep range failures ofien exhibited intercrystalline cracking. From the standpoint of fatigue, such an intercrystalline crack may be considered as replacing the crack developed by reversed strain cycling during the first part of the test. Experiments indicated that on smooth specimens the number of cycles required to initiate a crack of a few thousandths of an inch in depth is about $85 \%$ of the total life of the specimen. If it is assumed that intercrystalline cracking due to a "creep effect"' occurs early in the life, and thereby bypasses the transcrystalline crack-initiation period, the total life is approximately equal to only the crack propagation period. The life at high temperature is decreased to only about $15 \%$ of the value it might have achieved if intercrystalline cracking had not bypassed the crack-initiation period.

The above approach and other similar ones are discussed more fully in a number of references. An approach designated as the " $10 \%$ Rule"' has been adopted for further study. In this method, crack initiation and propagation are not considered as functions of life; rather it is assumed that, on the average, only $10 \%$ of the life computed by the method of universal slopes actually will be realized at temperatures within the creep range.

Generally, it has been found that such a computation yields conservative results. However, this approach inherently excludes the 
possibility of taking into account frequency effects, hold-time effects, mean load, etc.

One approach to take into account both the time at stress, or holdtime, and the frequency is outlined below. To simplify a complex problem the cyclic stress pattern is replaced by one in which the stress is constant and equal to the maximum tensile stress of the pattern it replaces. But the time for which it acts is chosen as only a fraction of the time required to complete the cycle. The assumption that the constant stress acts for about 0.3 of the total cycle time has yielded reasonable results, but this assumption readily can be altered as more information becomes available. Once the stress and the time which it acts have been selected, the creep effect can be calculated.

The simplified analysis that has been adopted can be explained by the following. ${ }^{62}$ The "creep damage" effect is taken as the ratio of the time actually spent at stress to the time required to cause rupture at that stress value. Since the stress and temperature are presumably known, this rupture time can be obtained directly from the creep-rupture curve of the material. The "fatigue damage" effect is taken as the ratio of the number of cycles actually applied to the number that would be sustained in the absence of "creep effect" according to the method of universal slopes. Since the test frequency yields a definite relation between the time of the test and number of cycles sustained, a closed-form analytical expression for the number of cycles to failure can be obtained. This description is shown in the following derivation:

$$
\begin{aligned}
& (\text { Creep-rupture damage })+(\text { Fatigue damage })=1 \\
& \left(\frac{\mathrm{t}^{\prime}}{\mathrm{t}_{\mathrm{r}}}\right)+\left(\frac{\mathrm{N}_{\mathrm{f}}^{\prime}}{\mathrm{N}_{\mathrm{f}}}\right)=1
\end{aligned}
$$

where

$$
\begin{aligned}
& t^{\prime}=\frac{k}{F} N_{f}^{\prime} \\
& t_{r}=A\left(\frac{\sigma_{r}}{1.75 \sigma_{u}}\right)^{1 / m}=A\left(N_{f}\right)^{-0.12 / m}
\end{aligned}
$$


hence

$$
\left(\frac{\mathrm{kN}_{\mathrm{f}}^{\prime}}{\operatorname{AF}\left(\mathrm{N}_{\mathrm{f}}\right)^{-0.12 / \mathrm{m}}}\right)+\left(\frac{\mathrm{N}_{\mathrm{f}}^{\prime}}{\mathrm{N}_{\mathrm{f}}}\right)=1
$$

or

$$
N_{f}^{\prime}=\frac{N_{f}}{1+k / A F\left(N_{f}\right)^{(m+0.12)} / m}
$$

where $\mathrm{N}_{\mathrm{f}}^{\prime}=$ number of cycles to failure under combined fatigue and creep.

$\mathrm{N}_{\mathrm{f}}=$ number of cycles to failure in fatigue, based on method of universal slopes, using ductility, ultimate tensile strength and elastic modulus from uniaxial tests at strain rates comparable to that experienced by the metal in the fatigue test. Where appropriate data are not available, use may be made of data from conventional tensile tests.

$\mathrm{k}=$ empirical constant, assumed to be 0.3 , but adjustable as more information becomes available.

$\mathrm{m}=$ slope of straight-line creep-rupture curve on $\log -\log$ coordinates, that is, representing curve by $\sigma_{\mathrm{r}}=1.75 \sigma_{\mathrm{u}}\left(\mathrm{t}_{\mathrm{r}} / \mathrm{A}\right)^{\mathrm{m}}$ as shown in the insert in Fig. 5. 14.

$A=$ coefficient in creep-rupture relation.

$\mathrm{F}=$ frequency of cycling, cycles per unit time.

In the foregoing section, two procedures for computing the lower bound on life have been outlined. They are:

1. By the " $10 \%$ Rule." The universal slopes (Eq. 5.45) are first used to determine cyclic life, and this life is divided by a factor of 10 .

2. By the combined creep and fatigue effect (Eq. 5.46).

The problem now is to determine which of the two equations to use, and how to interpret the results obtained from the computations. After considerable study of the data for many materials, the following conclusions can be drawn: 


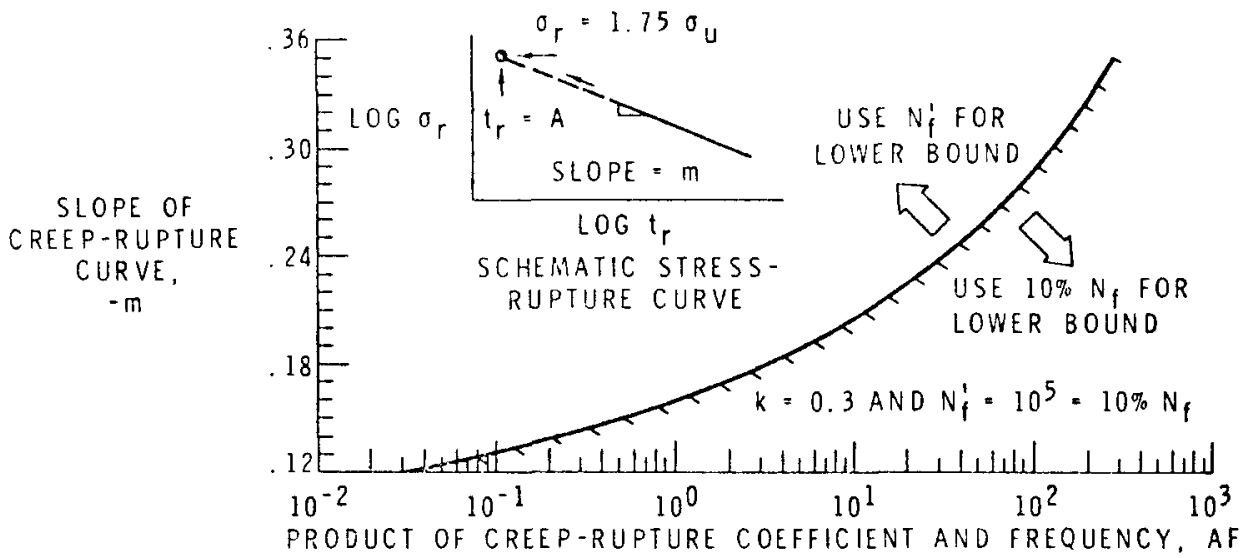

Fig. 5.14-Criterion to Establish Need for CreepRupture Correction 
a. Determine life by both methods (1) and (2) above, and use the lower of the two calculated values. Fig. 5. 14 is an auxiliary plot that minimizes the computations needed to determine which value to use. It is merely necessary to determine the product, $A F$, and the slope, $m$, of the creep-rupture curve at the test temperature. If the point representing the coordinates lies above the curve, use $\mathrm{N}_{\mathrm{f}}^{\prime}$ according to Eq. 5.46. If it lies below the curve, use the "10\% Rule."

b. The lower of the two values determined in (a) serves as a lower bound on estimated life.

c. As an estimate of average or most probable life, use twice the lower bound determined in (b).

d. As an estimate of the upper bound on life, use 10 times the lower bound determined in (b).

Thus, the method that has been adopted provides not only an estimate of the average life at a given set of test conditions, but also estimates of the upper and lower bounds within which the data are likely to fall. A study of how often these estimates have proven correct will be shown later. Also, although the method includes consideration of the "creepfatigue"' interaction, as shown by Eq. 5.46, it has been found that, in most cases encountered in the laboratory, the " $10 \%$ Rule" is the applicable one, eliminating the need for direct consideration of creep. Some creep interaction is implicitly included when the universal slopes life value is divided by 10 .

The above method has been applied to a large number of materials for which published fatigue data are available and a good correlation with test results is shown. However, it is emphasized that the data analyzed relate to constant-amplitude-strain cycling under constant temperature. While the method points to possible similar approaches for cases involving varying temperatures, varying strain amplitudes, complex stress histories, etc., it should be recognized that, in the present form, these deviations are not really included. It shows that the actual history of stress can be very important, emphasizing therefore the importance of hold-time, creep relaxation, and other factors contributing to the complexity of stress, but it approaches the question of stress determination in the most elementary form. More detailed studies are needed 
and more experimental data are necessary, based on the complex stress and temperature histories which may be expected in service.

\subsubsection{Local Strain Concentration}

Most fatigue data are based on laboratory specimens, but to determine fatigue life it is necessary to include the strain concentrating ef fects of geometric discontinuities and crack-like or other defects. Stress concentration factors for various geometries as well as strength reduction factors for a number of surface and subsurface defects are given in Reference 63. Additional data on stress concentration factors in circumferential fillets are given in References 64 through 68, and a computer code which has proved effective in determining these factors analytically is described in Reference 69.

\section{$\underline{5.3 .5 \text { Summary }}$}

Theoretical relationships have been developed showing the effects of temperature, strain rate, hold time, and creep on fatigue life. However, much more experimental data are required to verify these relations, to provide additional data on various materials, and to encompass sufficient temperatures, strain rates, etc., so that these procedures can be used with confidence to predict fatigue life over the complete range of design conditions, as well as for conditions not specifically covered by a fatigue test.

It is recommended that the procedures for fatigue evaluation in Code Case 1331 be used in the Piping Design Guide since the design fatigue curves are based on test data for the materials applicable for LMFBR piping, and represent the best procedures currently available for this purpose. 


\subsection{LOCAL STRAIN CONCENTRATIONS}

The problem of local strain concentrations in piping systems was first discussed by Robinson in 1955 (Reference 45, for further discussion also see Reference 51). Subsequent to the publication of Robinson's paper, the power piping code USAS B31.10 was revised to contain the following cautionary statement:

"All the commonly used methods of piping flexibility analysis assume elastic behavior of the entire piping system. This assumption is sufficiently accurate for systems where plastic straining occurs at many points or over relatively wide regions, but fails to reflect the actual strain distribution in unbalanced systems where only a small portion of the piping undergoes plastic strain, or where, in piping operating in the creep range, the strain distribution is very uneven. In these cases, the weaker or higher stressed portions will be subjected to strain concentrations due to elastic follow-up of the stiffer or lower stressed portions. Unbalance can be produced:

"(a) by use of small pipe runs in series with larger or stiffer pipe, with the small lines relatively highly stressed,

"(b) by local reduction in size or cross section, or local use of a weaker material, or

"(c) in a system of uniform size, by use of a line configuration for which the neutral axis or thrust line is situated close to the major portion of the line itself, with only a very small offset portion of the line absorbing most of the expansion strain.

"Conditions of this type should preferably be avoided, particularly where materials of relatively low ductility are used; if unavoidable, they may be mitigated by the judicious application of cold spring.

"It is recommended that the design of piping systems of austenitic steel materials be approached with greater over-all care as to general elimination of local stress raisers, inspection, material selection, fabrication quality and erection." 
As part of initial piping system evaluations, potential areas of strain concentration should be identified. These areas would be then subject to more detailed analyses to determine the amount and effect of the strain concentration on piping system life and performance.

Weld areas are particularly suspect, since in addition to geometric discontinuities which may exist, the weld metal properties such as strength, creep rate, and ductility may be significantly different than the base metal, resulting in concentrations of strain in the vicinity of the weld. In this regard, two recent publications (References 49 and 50 ) contain creep rupture data on welded materials of interest for LMFBR piping.

The analytical methods outlined in Section 5.1.4 would be applicable to evaluating these local areas of strain concentration. Robinson $^{50}$ assumed a creep law for a specific material and determined the strain concentrations for a few simple configurations (i.e., singleplane systems with square corners). For a critical piping system, such as the LMFBR primary loop, the need for a good plastic and creep analysis of the entire system seems well established. 


\section{RECOMMENDED R\&D REQUIREMENTS}

\section{1 DUCTILE RUPTURE}

As described in Section 5.1.2, experimental research is being done at Battelle Memorial Institute to determine what size defects in typical reactor piping are required to produce unstable fracture propagation in ductile materials. These tests are being conducted on A106-B carbon steel and Type 316 stainless steel and are to be extended to Type 304 stainless. It would be useful to extend this investigation to other materials, particularly $21 / 4 \mathrm{Cr}-1 \mathrm{Mo}$, for the LMFBR systems. It seems reasonable that a literature survey might add additional data to the failure stress for unflawed vessels, as well as the additional testing proposed.

\section{2 EXCESSIVE DISTORTION}

The most pressing requirement is to perform evaluations of experimental data to establish the validity of presently available analytical methods which include the effects of creep, plastic cycling and ratcheting. Experimental data to perform such evaluations are meager. The Pressure Vessel Research Committe ${ }^{70}$ had four cylindrical vessels with spherical heads tested in creep, but to date there has been no attempt to calculate the stresses and deformations either analytically by hand or with the digital computer. Membrane shells of constant stress ratio were tested by Gemma, Rowe, and Spahl. They also gave some analytical results which, unfortunately, did not agree very well with their experimental data.

A method was developed by Corum ${ }^{72,73}$ for predicting the instantaneous and creep buckling characteristics of initially out-of-round 
tubes subjected to lateral external pressure. Both the critical pressure causing collapse and the deformation of a tube at the instant of impending collapse may be determined by the method. The method was used to predict the instantaneous and creep buckling characteristics of a series of 8. 0-in. OD, Type 304 stainless steel tubes that were collapsed at a temperature of $1200^{\circ} \mathrm{F}$. Although the experimental tests did not represent an adequate sample, the instantaneous collapse pressure agreed closely with the predicted values, and the time-dependent collapse test results substantiated the observation that the theoretical creep-collapse predictions become increasingly conservative with time. Based on the work of Hoff et al. ${ }^{75}$ and Ellington, ${ }^{76}$ on the creep buckling of tubes under external pressure, Glükler, Passig, and Huchel ${ }^{74}$ derived equations to predict the increase in ovality of fuel element cladding under external pressure. The authors indicate that the results of autoclave tests at $1250^{\circ} \mathrm{F}$ and $2700 \mathrm{psi}$ on welded Inconel tubes were in satisfactory agreement with theory.

It is recommended, therefore, that a critical comparison between predictions of various analytical methods and available experimental methods be made, augmented by an experimental study in which representative geometries and loadings are tested in the creep range, and under conditions of plastic cycling. The computed and measured results then can be compared in order to resolve questions of the validity of analytical methods.

More experimental data on the basic creep properties of various materials are necessary, with particular emphasis on those suitable for use in the LMFBR program. Experimental testing of individual components under triaxial loading is also urgently needed to establish appropriate geometric factors.

\section{3 BRITTLE FRACTURE}

Considering brittle fracture, the most urgent need is for applied research in the fracture mechanics area. For immediate engineering purposes the principal research need is to delineate clearly the types of engineering situations to which fracture mechanics now can be applied, and to demonstrate its applicability, within stated limitations, to a wide variety of materials and geometries.

Before fracture mechanics can be applied with confidence to the design of engineering structures, model tests should be run on simple 
structures such as box beams or pressure vessels, with suitable cracks of various sizes introduced, to verify the results of fracture mechanics analysis utilizing fracture toughness determinations by "standard" laboratory methods.

Important parallel problems are slow crack growth preceding the onset of fast fracture under varying load conditions, and crack propagation under cyclic conditions, particularly at high stress levels, greater thicknesses, and higher temperatures.

There is a need to correlate the various methods by which fracture toughness is measured and to recommend a standard test procedure for future data.

More data should be obtained and summarized for low-alloy steels, particularly $21 / 4 \mathrm{Cr}-1$ Mo. This should represent normal conditions and also the effect of environment, such as sodium, irradiation, etc.

\section{4 FATIGUE}

Much more experimental data are required to establish fatigue curves and verify the various theoretical relations which have been developed, particularly for elevated temperatures. It is especially important in the creep range to determine the effect of hold-time at a given stress level, and also the closely related effects of strain rate and frequency. In addition, when loads of different magnitude are applied, the order of application has an important effect on the fatigue life.

\section{5 LOCAL STRAIN CONCENTRATIONS}

Of particular interest here would be local soft spots, such as might be induced by welding, where cyclic-plastic strain can be localized. A study should be directed toward defining situations in which this condition may exist and providing properties of materials in the heat affected zone. 


\section{BIBLIOGRAPHY}

1. Pellini, W. S.: Advances in Fracture Toughness Characterization Procedures and in Quantitative Interpretations to Fracture-Safe Design for Structural Steels, Welding Research Council Bulletin No. 130 (May 1968).

2. Brothers, A. J. et al.: A Review of Fracture Modes as Related to Reactor Primary Coolant Pipe Rupture, GEAP-4446 (May 1964).

3. Tagart, S. W., Jr.: Mechanical Design Considerations in Primary Nuclear Piping, GEAP-4578 (Mar. 1964).

4. Manson, S. S.: Fatigue: A Complex Subject - Some Simple Approximations, NASA TMX-52084 (Oct. 1964).

5. Miller, D. R.: Thermal-Stress Ratchet Mechanism in Pressure Vessels, Trans. ASME, J. of Basic Eng. (June 1959).

6. Investigation of the Initiation and Extent of Ductile Pipe Rupture, Progress Report for May-Dec. 1966, BMI-1793.

7. Ibid., Progress Report for Jan. -June 1967, BMI-1813.

8. Ibid., Progress Report for Oct.-Dec. 1967, BMI-1828.

9. Ibid., Progress Report for Jan.-Mar. 1968, BMI-1836.

10. Ibid., Progress Report for Apr.-June 1968, BMI-1847.

11. Irwin, G. R.: Structural Aspects of Brittle Fracture, Appl. Mater. Res., 3:65 (1964).

12. Griffith, A. A.: The Phenomenon of Flow and Rupture in Solids, Phil. Trans. Roy. Soc. London, A221, 163 (1920). 
13. Folias, E. S.: The Stresses in a Cylindrical Shell Containing an Axial Crack, Aerospace Research Laboratories, ARL 64-174 (Oct. 1964).

14. Dugdale, D. S.: Yielding of Steel Sheets Containing Slits, J. Mech. Phys. Solids, 8:100 (1960).

15. Swedlow, J. L. and Williams, M. L.: A Review of Recent Investigations into Inactive Initiation at Galcit, Aerospace Research Laboratories, ARL 64-175 (Oct. 1964).

16. Getz, D. L., Pierce, W. S., and Calvert, H. F.: Correlation of Uniaxial Notch Tensile Data with Pressure Vessel Fracture Characteristics, ASME Paper 63-WA-187 (Nov. 1963).

17. Symposium on Line Pipe Research, AGA publication L30000, p. 153, American Gas Association, New York (1966).

18. Pellini, W. S. and Puzak, P. P.: Fracture Analysis Diagram Procedures for the Fracture-Safe Engineering Design of Steel Structures, Welding Research Council Bulletin No. 88 (May 1963).

19. Puzak, P. P. and Pellini, W. S.: Standard Method for NRL DropWeight Test, NRL Report 5831 (Aug. 21, 1962).

20. Method for Conducting Drop-Weight Test to Determine Nil-Ductility Transition Temperature of Ferritic Steels, NavShips 250-634-3 (Aug. 21, 1963).

21. Irwin, G. R.: Relation of Crack Toughness Measurements to Practical Application, Welding Journal, 41:11, Research Supplement, 519-S to 528-S (1962).

22. Irwin, G. R. et al: Basic Aspects of Crack Growth and Fracture, NRL Report 6598 (Nov. 1967).

23. Pellini, W. S. and Puzak, P. P.: Practical Consideration in Applying Laboratory Fracture Test Criteria to the Fracture-Safe Design of Pressure Vessels, NRL Report 6030 (Nov. 5, 1963); also, Trans. ASME, Series A, J. Eng. Power, 86:429-443 (Oct. 1963).

24. Quirk, A.: A Maximum Stress Theory for the Failure of Pressure Components Containing Through Thickness Defects, AHSB(S)R 134 (1967). 
25. Quirk, A. and Bevitt, E.: An Elasto-Plastic Approach to Fracture Mechanics, AHSB(S)R 142 (1968).

26. Irvine, W. H.: The Application of Fracture Mechanics to the Design, Manufacture, and Operation of Critical Pressure Components, AHSB(S)R 143 (1968).

27. Beeckman, R.: Theoretical Bases of Fracture Mechanics, Welding Research Abroad, Vol. XIV, No. 9 (Nov. 1968).

28. Irwin, G. R.: Yielding Near a Crack and the Brittle-Ductile Transition, Lecture at the Fracture Mechanics Course, Belfast (Sept. 1967).

29. Wells: Application of Fracture Mechanics at and beyond General Yielding, British Welding Journal, 10, 11.

30. Hahn, Rosenfield: Local Yielding and the Extension of a Crack under Plane Stress, Acta Metallurgica, 13:293 (1965).

31. A Review of Engineering Approaches to Design Against Fracture, ASME (1965).

32. Marin, J.: "Mechanical Behavior of Engineering Materials," Prentice Hall, N. J., 1962.

33. Nadai, A.: "Theory of Flow and Fracture of Solids," Vol. I, 2nd Ed., McGraw-Hill Book Co., 1950.

34. Lubahn, J. D. and Felgar, R. P.: "Plasticity and Creep of Metals," John Wiley and Sons, N. Y., 1961.

35. Manson, S. S.: “Thermal Stress and Low Cycle Fatigue," McGrawHill Book Co., N。Y., 1966。

36. Langer, B. F.: PVRC Interpretive Report of Pressure Vessel Research, Section I - Design Considerations, Welding Research Council Bulletin No. 95 (1964).

37. Murphy, J. J. of M. W. Kellogg Co.: Letter to ASME Subgroup on Elevated Temperature Design dated September 3, 1968.

38. Robinson, E. L.: Effect of Temperature Variation on the Long Time Rupture Strength of Steels, Trans. ASME, 74:777 (1952).

39. Symposium on Effect of Cyclic Heating and Stressing of Metals at Elevated Temperatures, ASTM Special Technical Publication 165 (1954). 
40. DT-3-68 Life Fraction Rule, Report to Subgroup on Elevated Temperature Design, ASME Boiler and Pressure Vessel Code Committee, B. E. Bolton, June 10, 1968。

41. Timoshenko, S. and Goodier,J。N.: "Theory of Elasticity," p. 422, McGraw-Hill Book Co., 1951.

42. Finnie, I. and Heller, W. R.: 'Creep of Engineering Materials,', McGraw-Hill Book Co., 1959.

43. Kraus, H.: “'Thin Elastic Shells,' John Wiley and Sons, N. Y., 1967.

44. Sokolnikoff, I. S.: “Mathematical Theory of Elasticity," McGrawHill Book Co., 1956.

45. Robinson, E. L.: Steam Piping Design to Minimize Creep Concentrations, Trans. Am. Soc. Mech. Engrs. (Oct. 1955).

46. Hill, R.: “Plasticity,” Oxford Press, 1956.

47. Orowan, E.: Creep in Metallic and Non-Metallic Materials, Proc. First U. S. National Congress of Appl. Mech., ASME (1952).

48. Mendelson, A. and Manson, S. S.: Practical Solution of Plastic Deformation Problems in Elastic-Plastic Range, NCAA Technical Note 4088 (1957).

49. Johnson, E. W., McGraw, G. R., and Readal, R. L.: Fully Austenitic Stainless Steel Welding Electrodes for High Temperature Applications, Welding Research, Vol. 33, No. 12 (Dec. 1968).

50. de Barbadillo, J. J. et al.: Creep-Rupture Properties of Quenched and Tempered Pressure Vessel Steels - A Data Summary, Welding Research Council Bulletin No. 136 (Dec. 1968).

51. Kerkhof, W. P.: Stresses in Welded Pressure Vessels, Welding Journal, Vol. 35 (Jan. 1956).

52. Bree, J.: Elastic-Plastic Behavior of Thin Tubes Subjected to Internal Pressure and Intermittent High Heat Fluxes with Application to Fast-Nuclear Reactor Fuel Elements, J. of Strain Analysis, $2: 3$ (1967). 
53. Bree, J.: Incremental Growth Due to Creep and Plastic Yielding of Thin Tubes Subjected to Internal Pressure and Cyclic Thermal Stress, J. of Strain Analysis, 3:2 (1968).

54. Bree, J.: Ratchet and Enhanced Creep Strains in Sealed Fuel Pins for Nuclear Reactors, TRG Report 1311 (D) (1966).

55. Burgreen, D.: The Thermal Ratchet Mechanism, ASME, J. Basic Eng. (1968).

56. Burgreen, D.: Structural Growth Induced by Thermal Cycling, ASME Paper No. 68-WA/Met-14 (1968).

57. Coffin, L. F., Jr.: Low Cycle Fatigue, A Review, Appl. Mat'ls Res., 1:129 (1962).

58. Langer, B. F.: Design of Pressure Vessels for Low Cycle Fatigue, J. of Basic Eng., 84:389 (1962).

59. Coffin, L. F., Jr.: Introduction to High-Temperature, Low-Cycle Fatigue, Papers and Summary of Discussions Presented at SESA Spring Meeting, Ottawa, Ontario, Canada, May 16-19, 1967. Also, Experimental Mechanics (May 1968).

60. Lawton, C. W.: High-Temperature Low-Cycle Fatigue - A Summary of Industry and Code Work, Papers and Summary of Discussions Presented at SESA Spring Meeting, Ottawa, Ontario, Canada, May 16-19, 1967.

61. Manson, S. S.: A Simple Procedure for Estimating High-Temperature Low-Cycle Fatigue, Papers and Summary of Discussions Presented at SESA Spring Meeting, Ottawa, Ontario, Canada, May 16-19, 1967. Also, Experimental Mechanics (Aug. 1968).

62. Manson, S. S. and Halford, G. R.: A Method of Estimating HighTemperature Low-Cycle Fatigue Behaviour of Materials, Thermal and High Strain Fatigue, The Metals and Metallurgy Trust, London (1967).

63. RDT Reactor Standard, Reactor Coolant System Vessel Design Manual, RDT-S-918 (Oct. 1967).

64. Bynum, Douglas, Jr.: Fillet and Groove Stress Concentrations for Uniaxially and Biaxially Applied Loads, Southwest Research Institute, Project No. T-1677-3, Final Report (Aug. 27, 1962). 
65. Heifetz, J. H. and Berman, I.: Measurement of Stress Concentrations in the External Fillets of a Cylindrical Pressure Vessel, Foster Wheeler Corporation, Research Division, Final Report to PVRC (Dec. 1966).

66. Griffin, D. S. and Thurman, A. L.: Stress Concentration Factors for External Fillets on Pressurized Cylinders, Westinghouse Electric Corporation, Report WAPD-FD(MA)-25.

67. Griffin, D. S. and Thurman, A. L.: Comparison of DUZ Solution with Experimental Results for Uniaxially and Biaxially Loaded Fillets and Grooves, WAPD-FD(MA)-26.

68. Heifetz, J. H. and Berman, I.: "Measurements of Stress Concentration Factors in the External Fillets of a Cylindrical Pressure Vessel,' Experimental Mechanics, Dec. 1967.

69. Griffin, D. S. et al.: DUZ-1: A Program for Solving Axisymmetric and Plane Elasticity Problems on the Philco-2000, WAPD-TM-555 (Nov. 1965).

70. PVRC Subcommittee on Effects of Fabrication on Materials for High Temperature Service: High Temperature Creep Tests on Model Pressure Vessels, Welding Research Supplement (Aug. 1965).

71. Gemma, A. E., Rowe, G. H., and Spahl, R. J.: Elastic and Creep Characteristics of a Class of Shell Closures with Constant Stress Ratio, Trans. Am. Soc. Mech. Engrs., Vol. 83D (1961).

72. Corum, J. M.: An Investigation of the Instantaneous and Creep Buckling of Initially Out-of-Round Tubes Subjected to External Pressure, ORNL-3299.

73. Corum, J. M. and Greenstreet, B. L.: An Experimental Investigation of Instantaneous Collapse and Creep-Buckling Characteristics of Cylindrical Shells, ORNL-3555 (Mar. 1964).

74. Glükler, E. et al.: Creep Buckling of Fuel Element Cladding, Nuclear Eng. and Des., 7 (1968).

75. Hoff, N. J. et al.: A Study of Creep Collapse of a Long Cylinder under Uniform External Pressure, J. of the Aerospace Sciences, $26(1959)$. 
76. Ellington, J. P.: Creep Collapse of Tubes under External Pressure, UKAEA DEG Report $162 \mathrm{R}$. 


\section{APPENDIX A - HISTORICAL EVENTS LEADING TO} THE NEW ASME CODE TUBE FORMULA 
HISTORICAI EVENTS LEADING TO

NEW ASME CODE TUBE FORMULA

The formula used by the ASME Boiler and Pressure Vessel Code for setting minimum wall thickness in tubes has undergone a long and hard-fought period of development. This report reconstructs the chronological events leading to the adoptment of the new formula.

Prior to 1935, the Cods Formula was:

$$
P=\frac{18000(t-0.039)}{D}-250 \text {, or } t=\frac{P D}{18000}+0.0139 D+0.039
$$

for seamless tubes and for welded tubing for pressures under 875 psi.

$$
P=\frac{14000(t-0.039)}{D} \text {, or } t=\frac{P D}{14000}+0.039
$$

for welded tubing for pressures above 875 psi.

In the 1940 Code, paragraph P-22 referred to maximum allowable working pressures listed in Table P-2 for seamless carbon steel tubes. For low tensile carbon steels ( 45 to 48000 psi UTS), the formula used was:

$$
P=\frac{20700(t-0.04)}{D}-300, \text { or } t=\frac{P D}{20700}+0.0145 D+0.04
$$

For the higher tensile carbon steels (60,000 psi UTS), the formula was:

$$
P=\frac{27600(t-0.04)}{D}-400 \text {, or } t=\frac{P D}{27600}+0.0145 D+0.04
$$

For elevated temperatures, the value of the stress factor $S$ was taken from Table P-5 and used in the formula:

$$
P=\frac{2.3 S t}{D}-\frac{S}{30} \text {, or } t=\frac{P D}{2.3 S}+0.0145 D
$$

where $S=80 \%$ of the stress for $1 \%$ Creep in 100,000 hours at a temperature equal to the mean wall temperature.

In 1942 the $S$ values were permitted to be increased by a factor of 1.25 which brought $S$ up to the full 1\% creep in 100,000 hours.

As a result of this revision, the May 19, 1944, Addenda added paragraphs P-401 through P-409 to the 1943 Code. 
This "Alternate Code" resulted in formula (3) becoming

$$
P=\frac{25875(t-0.04)}{D}=405 \text {, or } t=\frac{P D}{25875}+0.0156 D+0.04
$$

and formula (4) changed to

$$
P=\frac{34500(t-0.04)}{D}-540 \text {, or } t=\frac{P D}{34500}+0.0156 D+0.04
$$

At the same time, a hydrostatic test pressure of at least 1.5 times the maximum allowable working oressure was required by paragraph $\mathrm{P}-408$.

The August 25, 1944, Addenda revised Table P-2 and ad led to it formulas (6), (7) and (5), the J'st ons orroneously.

The 1946 Code listed the revised Table P-2, and the typographical error made in adding formula (5) was corrected in the July 26, 1948, Addenda by replacing formulas (5) as follows:

$$
P=\frac{2.875 S(t-0.04)}{D}=0.045 \mathrm{~S} \text {, or } t=\frac{P D}{2.875 S}+0.0156 D+0.04
$$

This formula was discussed in detail by P. M. Brister in his "Report on the Use of Carbon Steel and Steel Alloys in Superheater Tubes", dated August $26,1946$.

The 1949 Code carried the same paragraph P-22 and Table P-2. However, work was already under way to renovate the entire concept of formula and allowable stress tables. Cur I'. M. Brister, R. L. Whitelaw, J. F. Wachunas and L. F. Kooistra were deeply involved in the study of available data on rupture to decide on a new tube formula which would correlate design stress with stressrupture data. There was a great lack of adequate data.

In January, 1951, Mr. Martin Frisch of Foster Wheeler, Chairman of the Subcommittee on Tube Thickness, suggested the "Thin Tube Formula" as the standard formula for boiler and superheater tubes. Impetus to the drive for thinner tubing (and corresponding materials conservation) was given by the Department of Commerce, National Production Authority, probably as a result of the Korean crisis.

W. J. Buxton and R. W. Burrows, of Standard Oil of Indiana, in ASME Paper 50-A-62, proposed the following formula (No. 49 in the paper):

$$
s=\frac{P D}{2 t}+0.2 P \text {, or } t=\left(\frac{P / S}{0.8 P / S+1}\right) \frac{D}{2}
$$

An advanced draft of this paper was available to the committee early in 1951 as a B31 task group report, about a year before publication. 
In a discussion of this paper, Mr. A. W. Rankin, of General Electric Company, also recommended this formula. Mr. Frisch partially supported this view and submitted a comparison of various formulas, attached to this letter as Figure 1. E. J. Wiseman of Stone \& Webster also approved this formula or the Boardman modified Lamé formula. Our Mr. Whitelaw discoursed greatly on both the G. E. paper and Rankin's discussion, objecting to equations based on "feelings" and supporting the Thin Tube Formula as a realistic design formula for long life tubes undergoing creep. This formula included a corrosion allowance:

$$
t=\frac{P / S}{P / S+1} \frac{D}{2}+0.0156 D
$$

The progress report of the Subcomittee stated that: "Over the range of $\mathrm{P} / \mathrm{S}$ values from 0 to 0.3 , applicable to economizer and boiler tubes for the very highest pressures now in use or contemplated, thicknesses calculated by the Mean Diameter and Thin Tube equations are nearly the same as those calculated by Formula C, Table P-2 (My note: Eqn. (8) of this letter). Over the range of 0.5 to 1.0 , not unusual in high pressure high temperature superheaters, only the Thin Tube Formula gives practical bore and thickness ralves, ss show by Figure 1 (My note: My Figure 1). Table I (attached) shows hu aisely percentagewise these thicknesses compare with those of Formula C, Table P-2 (Eqn. (8))." The report proceeds to quote Dr.J. S. Blair, of Stewarts and Lloyds, Ltd., in his paper: "Stresses in Tübes Dué to Internal Pressure", Engineering, September 15, 1950, and states that "the use of the Thin Tube Formula appears justified for calculating tube thicknesses subjected to stresses in the plastic range, because the stress readjustments caused by creep tend to equalize the stresses across the tube wall and to produce a uniform axial and circumferential stress distribution, resulting in lower values than calculated by the Lamé. equations which apply under elastic conditions only".

P. M. Brister arrived at the Thin Tube Formula, although by different reasoning. He quoted the B\&W Tubular Stress Rupture work and Creep programs underway at that time. He also recommended that the allowable stresses should be set on the average wall temperature instead of his previous recommendation of using the outside wall temperature.

H. Weisberg, of Public Service Electric and Gas Co. also preferred the Thin Tube Formula and the average wall temperature as did Dr. G. V. Smith, then at United States Steel Company, now at Cornell.

On March 9, 1951, the proposed revisions of paragraphs P-21 and P-22, incorporating the Thin Tube Formula, were approved by the Boiler Code Committee. At this time, concern for thinner tubes for low and intermediate pressures was expressed by P. R. Cassidy in casting a negative vote. Both he and A. C. Weigel (also voting no) opposed eliminating Table P-2; Mr. Frisch also voted no to permit the subcommittee to revise its proposal. The table was revised and included in the rewrite, to overcome the two objections and, on August 8, 1951, the revisions of the paragraphs were approved with this formula for tubes:

$$
t=\frac{D}{2}\left[\frac{Y}{Y+1}\right]+0.0135 D+e,
$$


where $Y=P / S=\frac{2 t-0.027 D-2 e}{D-(2 t-0.027 D-2 e)}$

and $e=0.04$ over a length at least equal to the length of the seat plus one inch, for tubes expanded into tube seats

or $e=0$ for tubes strength welded to headers and drums.

All the preceding formulas, (1) through (11), are variations of the hoop stress formula, $S=\frac{P D}{2 t}$, and the Mean Diameter formula is the hoop stress measured at $D=D_{m}$.

At the ASME Annual Meeting in Atlantic City, N.J., November 25, 1951, L. F. Kooistra, R. U. Blaser and J. T. Tucker, Jr., (Paper 51-A-44) wrote on "High Temperature Stress-Rupture Testing of Tubular Specimens". This was one of the earlier works in this field and has been widely quoted.

During the next five years little Code activity transpired to change the status quo. On August 8, 1956, P. M. Brister notified G. W. Kessler of the apparent lack of correlation of data. Meanwhile our R\&D personnel were developing more rupture data and the results led to an internal report to the B\&W Superheater Materials Committee, first prepared by J. T. Tucker on September 7, 1956, entitled:. "Inadequacy of ASME Code Formulz in the Design of Heavy-Wall

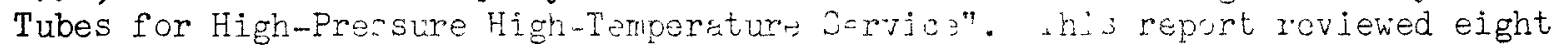
years of testing and concluded that the ASME formula gave excellent correlation between thin wall tubular specimens and coupon specimens of the same heat. Stress-ruoture tests made on heavy-wall tubing indicated that the life of these tubes was considerably shorter than that for coupon specimens of the same heat of material. The report proceeds to state: "It is evident, therefore, from the above data and from residual stress studies that the creep or relaxation of high stresses expected in the first few hundred hours does nct take placo to the degree necessary to produce neariy constant jtrass throughout the tube wall. Apparently we are faced with an anomalous situation wherein the allowable design stress for boiler tubes is selected primarily on the basis of plastic properties such as creep rate and stress rupture life, but tubes seem to fail according to elastic laws. Undoubtedly at sufficient high temperatures, the expected equalization would occur, but apparently the temperatures at which this takes place are well above the use limits of boiler materials.

"The implications of designing heavy-wall tubes by the present code formula are quite serious, since tubes will fail prematurely in service. For example, if a $2 "$ OD tube of Croloy $2 \frac{1}{4}$ were designed according to the old boiler code (prior to 1952) for a mean temperature of $1100 \mathrm{~F}$ and a pressure of 2500 psi, it would have a stress rupture life in excess of 40 years. However, a tube designed using the present code for the same conditions would experience a stressruoture failure in annroximately 10 years." With minor revisions this report was again issued by Tucker on January 28, 1958, under the title: "Effect of Tube Wall Thickness on Stress-Rupture Life at Elevated Temperatures". 
On November 14, 1957, G. W. Kessler commented on the Superheater Materials Committee recomnendation to publish a paper which would disclose the B\&W test information. On December 18, 1957, a group of B\&W personnel chairmaned by G. N. Emmanuel recommended that: "The B\&W Co., through its regular code representatives, arrange a special meeting with selected personnel from Foster Wheeler and Combustion Engineering, and other mutually agreed upon Boiler Code people for the purpose of disclosing and discussing the information The B\&W Co. has obtained in the tubular stress-rupture tests." This action was confirmed by Kessler and Rowand.

In February 7, 1958, G. N. Emmanuel suggested an interim formula combining the code formula (for $D / t$ of 9 or greater) and the Lamé formula (for $D / t$ less than 9), as a conservative method of calculating tube thicknesses:

$$
t=0.382 D(P / S+0.053)
$$

During this time the Babcock and Wilcox Company approached other producers and revealed its findings. Enough agreement was received to decide that the Code Committees should.be made aware of the developments. In March 1958, a Task Group on Tube Formula was formed under the ASME Subcommittee on Power Boilers. Members were J. L. Menson, Chairman, P. M. Brister (for F. X. Gilg), E. C. Korten, and E. J. Wiseman, with W. R. Burrows, E. A. Davis, J. W. Freeman, and $L$. F. Kooistra as consultants. The B\&W report was distributed and the task group was charged with the job that
a) The Code formula provide the expected life of tubes whether thick or thin-walled, and whether in the elastic or the creep range.

b) Adequate correlation between bar and tubular specimen tests be achieved to permit use of the much greater amount of bar data.

In October 27, 1958, the Task Group held its second meeting. Combustion Engineering data on Type 321 Stainless Steel was distributed, as well as B\&W data on the same material. Union Carbide Corporation was invited to participate in the Task Group by virtue of their work on tubular rupture testing conducted on very heavy wall tubes. Westinghouse supplied triaxial stresses on type 316 stainless steel.

At the April 30, 1959, meeting it was agreed to do additional testing (B\&W on type 304 Stainless, CE on 9 Chrome), supply additional data (Union Carbide on Type 347, Westinghouse on Type 347, B\&W on the ASME Solberg tests), and gather all available data (European).

At the ASME Metals Engineering Conference, Albany, N.Y., April 29 - May 1, 1959, Tucker, E. E. Coulter, and Kooistra presented a paper (59-Met-11) on the "Effect of Wall Thickness on Stress-Rupture Life of Tubular Specimens". In this paper the inadequacy of the basic thin tube formula, $S=\frac{P D_{i}}{2 t}$, was
discussed. 
On August 28, 1959, as a result of their investigations on B\&W supplied material, C.E. reported low strengths on Croloy 9 tubing. Analysis of the data by $W$. E. Leyda indicated, that, while this material would rank with the lowest values listed on ASTM STP-151, the material "is a good acceptable material from the standpoint of rupture strength". Tubular Products Division was also of this opinion.

On November 25, 1959, Union Carbide submitted its data, which was evaluated by B. E. Bolton. On April 21, 1960, he substantiated the fact that Code Formula P-22 for thick wall tubes was inadequate.

On September 8, 1961, B. E. Bolton reported on his analysis of the Babcock \& Wilcox, Ltd., report: "A Design Formul a for High Pressure Tubes Operating Under Creep Conditions". This report listed British, Russian and some of our American tubular stress-rupture and basic bar data. It showed that the tubular stress-rupture data best fits the bar data when the tube stress was calculated by the mean diameter formula. He agreed with the British recommendation that the piping formula, P-23, be used for tubes with $Y=0.5$ in the creep range, and 0.4 below the creep range. The first value of $Y$ results in the mean diameter formula, and the second value makes P-23 approximately the same as the Lamé formula.

On Jantary 2, 1962, P. M. Brister recommended the British formula, but recommended evaluating the variations shown by American data.

The Task Group met again on April 24, 1962, with a recommendation from L. F. Kooistra for the consideration of the following formula:

$$
\mathrm{T}=\frac{\mathrm{PD}}{2 \mathrm{~S}+\mathrm{P}}+0.007 \mathrm{D}+\mathrm{e}
$$

The comparison of seven formulas is shown on Figure 2, attached.

On May 2, 1962, W. L. Harding submitted an interim report to the Subcommittee on Power Boilers, noting the need for a revision of tube formula P-22, especially for "thick-walled tubes operating in the high temperature range where creep and stress-ruoture behavior prevail".

On June 5, 1962, B\&W submitted the final results of its tubular stressrupture tests on type 304 stainless at $1200 \mathrm{~F}$. L. F. Kooistra reported that the $0.0135 \mathrm{D}$ added to all tubes by the 1951 formula was insufficient for thick tubes and was unnecessary for the thin tubes where experience was satisfactory.

On June 14, 1962, Kooistra again recapitulated the work to date, and explained that the $0.007 \mathrm{D}$ factor was included to make the new formula more conservative than present $\mathrm{P}-22$ in the region for $\mathrm{D} / \mathrm{t}$ values from 6 to 11 , although there is no reason, stresswise, to have an additive term at all.

On November 2, 1962, W. L. Harding presented a summary to the Boiler and Pressure Vessel Code Committee, after the Subcommittee on Fower Boilers had voted to revise P-22 (a) to 


$$
t=\frac{P D}{2 S+P}+0.005 D+e
$$

Mr. Harding emphasized the importance of this change, especially since it will result in an increase in the cost of manufacturing boilers. This summary is attached to this report. formula.

At the January 11, 1963, meeting, the Main Committee adopted the new

At the June 20, 1963, meeting it was voted to limit the minimum tube wall thickness to the smallest thickness for that diameter of tube for which a pressure rating is listed in table P-2. There was a negative vote, and on September 12, 1963, the June action was rescinded.

In summary, Mr. Harding's task group report merits being quoted verbatim:

"The evidence that the old tube formula was not technically correct was discovered in laboratory tests from tubular rupture tests. The data which revealed this deficiency has been supported by tests in independent laboratories to the point that sufficient data was available to provide a more technically correct formula. Field experience did not reveal this deficiency because thickness of most tubes in the critical range is based on creep data which provide more thickness than is required by rupture data. There are no satisfactory methods available for obtaining creep data on tubular specimens. Also the use of commercially available thicknesses usually provide thickness greater than minimum required. Also design pressure is used, and there is often several hundred pounds per square inch operating pressure drop between drum and superheater tubes.

"The trend in design to once-through boilers with stepped pressure design to the use of higher levels, and the reduction in the factor of safety for nuclear vessels warrants changing the tube formula to make it as technically correct as possible".

The formula revision has been published in the May, 1963, issue of Mechanical Engineering. It has been issued in the December 31, 1963, addenda to Section I. It becomes mandatory on June 30, 1964 .

MNB:mg

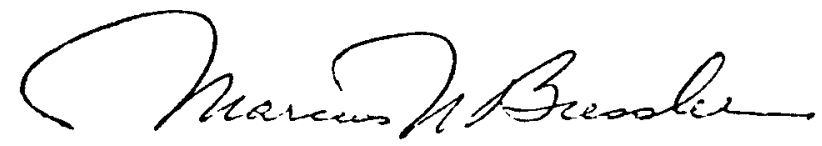

Marcus N. Bressler

Design Engineering Technology<smiles></smiles> 
THE BABCOCK \& WILCOX CO

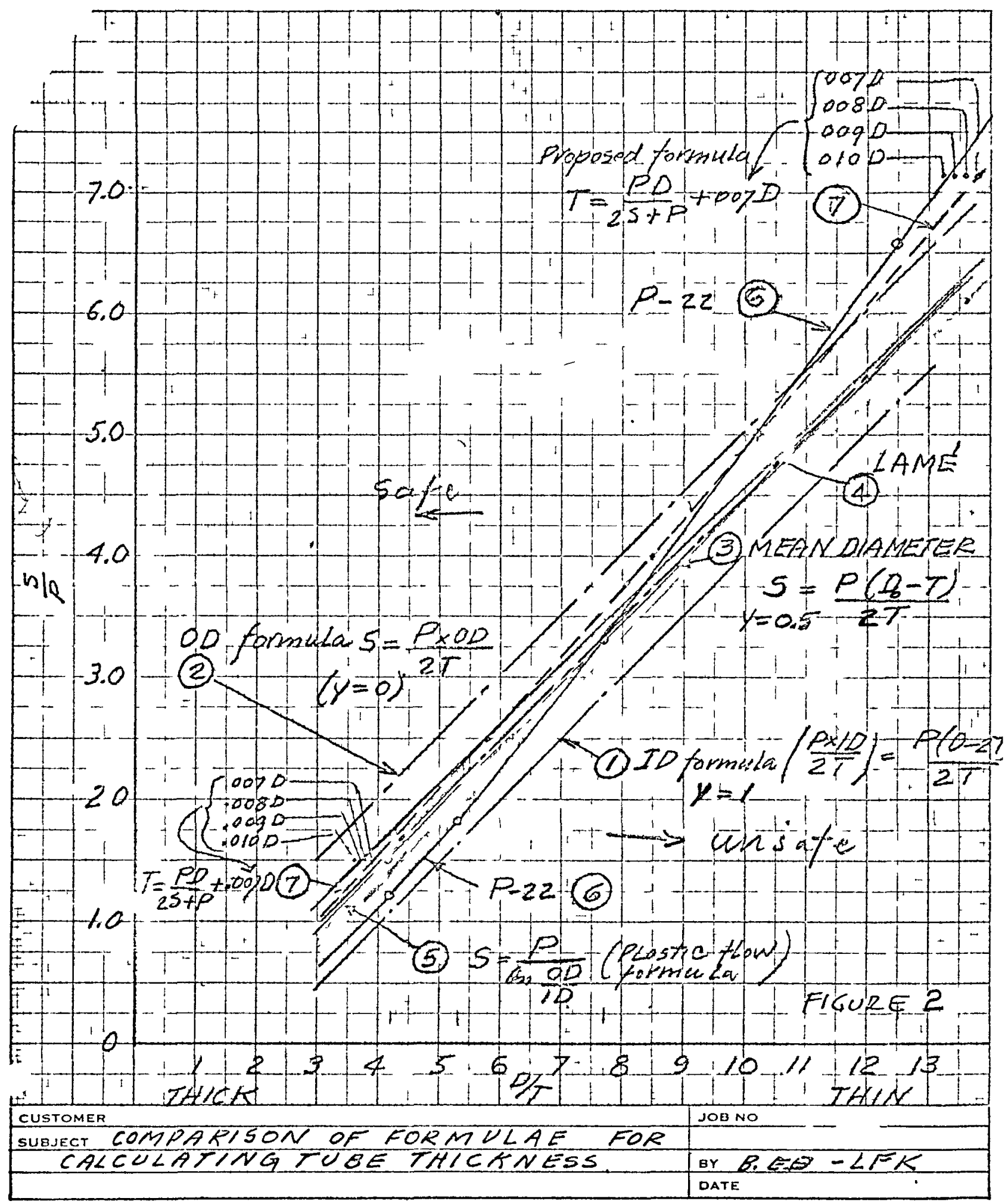

